\title{
CHARACTERIZATION OF LANDFILL MINING MATERIAL AFTER BALLISTIC SEPARATION TO EVALUATE MATERIAL AND ENERGY RECOVERY POTENTIAL
}

\author{
Cristina García López ${ }^{1, *}$, Anita Ni ${ }^{1}$, Juan Carlos Hernández Parrodi ${ }^{2,3}$, Bastian Küppers ${ }^{3}$, \\ Karoline Raulf ${ }^{1}$ and Thomas Pretz ${ }^{1}$
}

${ }^{1}$ Department of Processing and Recycling, RWTH Aachen University, Aachen, 52062, Germany

${ }^{2}$ Renewi Belgium SA/NV, Gerard Mercatorstraat 8, 3920 Lommel, Belgium

${ }^{3}$ Chair of Waste Processing Technology and Waste Management, Montanuniversität Leoben, Leoben, 8700, Austria

Article Info:

Received:

30 October 2018

Revised:

31 January 2019

Accepted:

22 February 2019

Available online:

01 August 2019

Keywords:

Enhanced landfill mining

Refuse derived fuel

Mechanical pretreatment

Ballistic separator

Recycling

Waste-to-energy

Waste-to-materia

\section{ABSTRACT}

For decades, ballistic separators have been used in Europe as a means of sorting waste to separate mixed waste material streams at material recovery facilities and municipal solid waste treatment plants. Currently, with the growing need to remediate landfill sites, ballistic separators can be employed to recover calorific fractions from excavated landfill material within the framework of enhanced landfill mining. Ballistic separators provide multiple separation steps in one machine: they sort flat two-dimensional materials from rigid three-dimensional materials, while the material is screened to a selected particle size at the same time. The present study shows the results obtained during an investigation performed at the landfill in Mont-Saint-Guibert, Belgium. The main objectives were to acquire first-hand information regarding the efficiency of the ballistic separator in relation to processing old and untreated landfilled material and to study the potential of the landfill as a reservoir of secondary resources. The excavated material was processed through a pre-treatment chain of steps, including material classification and separation, as well as particle size reduction. As a first step, the material was processed with a ballistic separator using two different mesh sizes, $200 \mathrm{~mm}$ and $90 \mathrm{~mm}$. Subsequently, the performance of the separator in question was evaluated, especially regarding its effectiveness in the production of refuse derived fuel. The two-dimensional flow was characterized by combustible materials from municipal solid waste and the three-dimensional by construction and demolition waste. As a result, $46 \%$ (dry basis) of the input material were fines particles $<20 \mathrm{~mm}$, $3 \%$ had a calorific value of $22.4 \mathrm{MJ} \mathrm{kg}^{-1}, 1 \% 16.0 \mathrm{MJ} \mathrm{kg}^{-1}$ and approximately $1 \%$ were magnetic metals that could be recovered by mechanical processes. The results of processing and valorising the potential resources disposed in landfills are essential for the implementation of enhanced landfill mining since revenues from material and energy recovery could contribute to the economic feasibility of the project.

\section{INTRODUCTION}

As the global demand for raw materials rises, while the availability of natural resources remains limited, alternative sources of materials demand investigation and, therefore, new techniques need to be developed in order to maximize the use of existing materials. A political framework to tackle these challenges was set by the 2020 Strategy of the European Union (EU). This strategy serves as the basis for the 7th Environment Action Programme, which seeks to develop a sustainable, low-carbon and resource-efficient economy where waste is turned into a resource (European Parliament, 2013). Regarding historic waste, it is of major interest to identify the potential and examine which secondary resources could be recovered from the existing 150,000 to 500,000 landfills that are estimated to be located in the EU (Hogland et al., 2010). This subject is investigated in enhanced landfill mining (ELFM) projects, which aim for "the safe conditioning, excavation and integrated valorisation of (historic and/or future) landfilled waste streams, both as materials (Waste-to-Material, WtM) and energy recovery (Waste-to-Energy, WtE), using innovative transformation technologies and respecting the most stringent social and ecological criteria" (Jones et al., 2013). ELFM contributes to create a circular economy and to reduce the EU's dependency on imports of raw materials, driven by the goals of reclaiming land, re- 
gaining landfill capacity and protecting groundwater, as has previously been achieved by landfill mining (LFM) projects (Hermann et al., 2014; Hernández Parrodi et al., 2018a).

This study focuses on the characterization of landfilled material that was directly processed with a ballistic separator after excavation. Figure 1 shows the working principle of a ballistic separator, which is a standard processing equipment, normally installed in packaging waste treatment plants before sensor-based sorting or after infeed with subsequent drum screen. Due to the inclination and upward movement of the paddles, three-dimensional (3D) materials (heavy, hard and round particles) move downwards and are separated from the two-dimensional (2D) materials (lighter and soft particles), such as plastics, paper and textiles, which are collected at the top end of the paddles. A third output stream, the under-sieve fraction, is produced due to the screening property of the paddles. The latter can be varied by adjusting the screen of the paddles according to a certain particle size. Material characteristics, such as weight, form, size and elasticity, can influence the movement of the particles and can, therefore, affect the sorting efficiency of the equipment.

A bottom-up approach, in contrast to a top-down approach analysing historical data (Bhatnagar et al., 2017), was chosen in this study. Especially since most older landfill sites did not register the type and amount of material deposited during their active phase (Jones et al., 2013). However, landfilled materials are heterogeneous waste streams that need to be separated and treated before they can be recovered (Quaghebeur et al., 2013). Previous studies provide information on the applicability of full-scale and state-of-the-art technology used currently in waste-treatment plants (García López et al., 2018; Kaartinen et al., 2013; Maul \& Pretz, 2016).

The novelty of this case study is the use of a ballistic separator as the first step of the mechanical process prior to shredding. This method allows the recuperation of fractions that are suitable for the production of refuse derived fuel (RDF) with a high heating value in its original size, in addition to other valuable materials, such as inert, glass and metallic materials.

Landfilled waste from which RDF might be produced includes plastics, paper, wood and textiles (calorific fractions). In addition, metals, glass and perhaps mineral and organic materials could be recovered (Kaartinen et al., 2013; Quaghebeur et al., 2013). The material composition of landfill sites varies according to different factors, such as the time of deposition, the type of stored waste, the meteorological and hydrological conditions of the site, and the collection area, since waste composition is influenced by population density, consumer behaviour and waste-sorting habits (Quaghebeur et al., 2013; Wolfsberger et al., 2015a). Therefore, a holistic characterization of the landfilled waste contributes to assessing the suitability of a site for ELFM, which is determined by the share of usable recyclables from the excavated waste, among others, and to predict the revenue and costs of an ELFM project (Hermann et al., 2014).

The purpose of this study is to evaluate the performance of the ballistic separator "STT 6000"-STADLER ${ }^{\circledR}$ Anlagenbau $\mathrm{GmbH}^{\prime}$ with landfilled material. This evaluation was achieved by characterizing each output stream of the ballistic separator. The materials composing these streams were identified by manual sorting and were subjected to laboratory analyses, such as moisture content, particle-size distribution (PSD), calorific value and ash content, to obtain qualitative and quantitative information and determine the suitability of the calorific fractions for the production of RDF.

\section{MATERIALS AND METHODS}

\subsection{Site description}

The examined landfill site is located in the municipality of Mont-Saint-Guibert (MSG) in the province of Walloon Bravant, Belgium. This site was established on a former sand

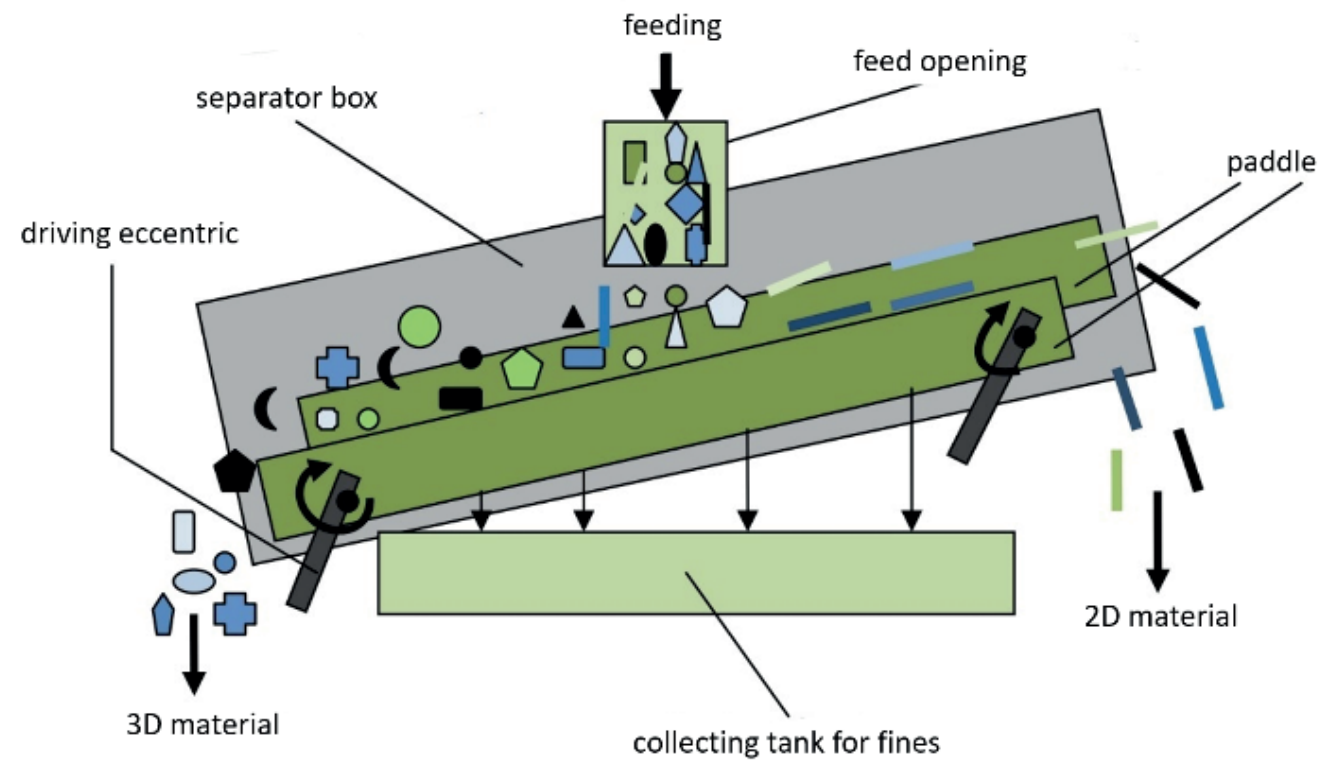

FIGURE 1: Schematic diagram of a ballistic separator (adopted from Martens \& Goldmann, 2016). 
quarry and has served as one of the main disposal sites of municipal solid waste (MSW), non-hazardous industrial waste and construction and demolition waste (CDW) since 1958 (Bureau d'études greisch, 2002). The site covers an area of approximately 44 ha, of which 26 ha belong to the most recent part and 2 ha to the oldest part. The oldest part of the site has no bottom liner and, nowadays, the biogas collection system has been removed, while the leachate collection system is still in place and operational. The present investigation was carried out in the old part of the landfill, which has an estimated depth between $30 \mathrm{~m}$ and $60 \mathrm{~m}$ and where at least 5.7 million $\mathrm{m}^{3}$ of waste were deposited between 1958 and 1985 (Hernández Parrodi et al., 2018b).

In September 2017, before the excavation, a geophysical exploration was performed in an area of approximately $2150 \mathrm{~m}^{2}$. Using electromagnetic induction, the depth of the cover layer and the soil properties were estimated. Based on the results of the electrical conductivity, the area was then divided into four batches. This paper focusses only on batch 1. A future publication will show the results of all four batches.

As shown in Figure 2, the waste was covered by a clay layer with a thickness of about $4 \mathrm{~m}$. This layer was removed in order to keep it separated from the landfill waste. The processed pit was $5 \mathrm{~m}$ long, $5 \mathrm{~m}$ wide and $4 \mathrm{~m}$ deep; a total volume of $130 \mathrm{~m}^{3}$ was excavated and treated. During the excavation, a layering of different types of materials was observed. From top to bottom: $4 \mathrm{~m}$ cover layer, $2 \mathrm{~m}$ CDW and $2 \mathrm{~m} \mathrm{MSW}$. For the extraction of the buried material, an excavator with a toothed digging-type bucket was employed, while for the manipulation of the excavated material a wheel loader was used. The weight of the material was measured with a weighing bridge (resolution of $50 \mathrm{~kg}$ ).

\subsection{Mechanical processing and sampling campaign}

After the excavation, the material was directly fed into the ballistic separator "STT 6000", the specifications of which are given in the Appendix. The motivation for the choice of this specific equipment was the following: i) the conglomerates of the input material would be loosened up due to the agitation (crankshaft eccentricity) on the screen deck, ii) its availability for treating CDW (Sigmund, 2018), iii) no pre-shredding of the input material is needed (saving the wear and energy on the shredders for the infeed material), iv) sorting large items increases sorting quality (large parts can be removed in one piece), v) saving of space on the site due to the separation of 3 fractions in one step (vs. a drum type, by which only particle size can be sorted), and vi) its robust design. Thus, these characteristics could lead to better sorting processes (enhanced mechanical treatment) with respect to effectiveness, wear and energy consumption. Even if previous studies recommend low moisture content (<15\%) for an effective sorting process (Giani et al., 2016; Martens \& Goldmann, 2016), this study was performed without drying the material prior to the processing.
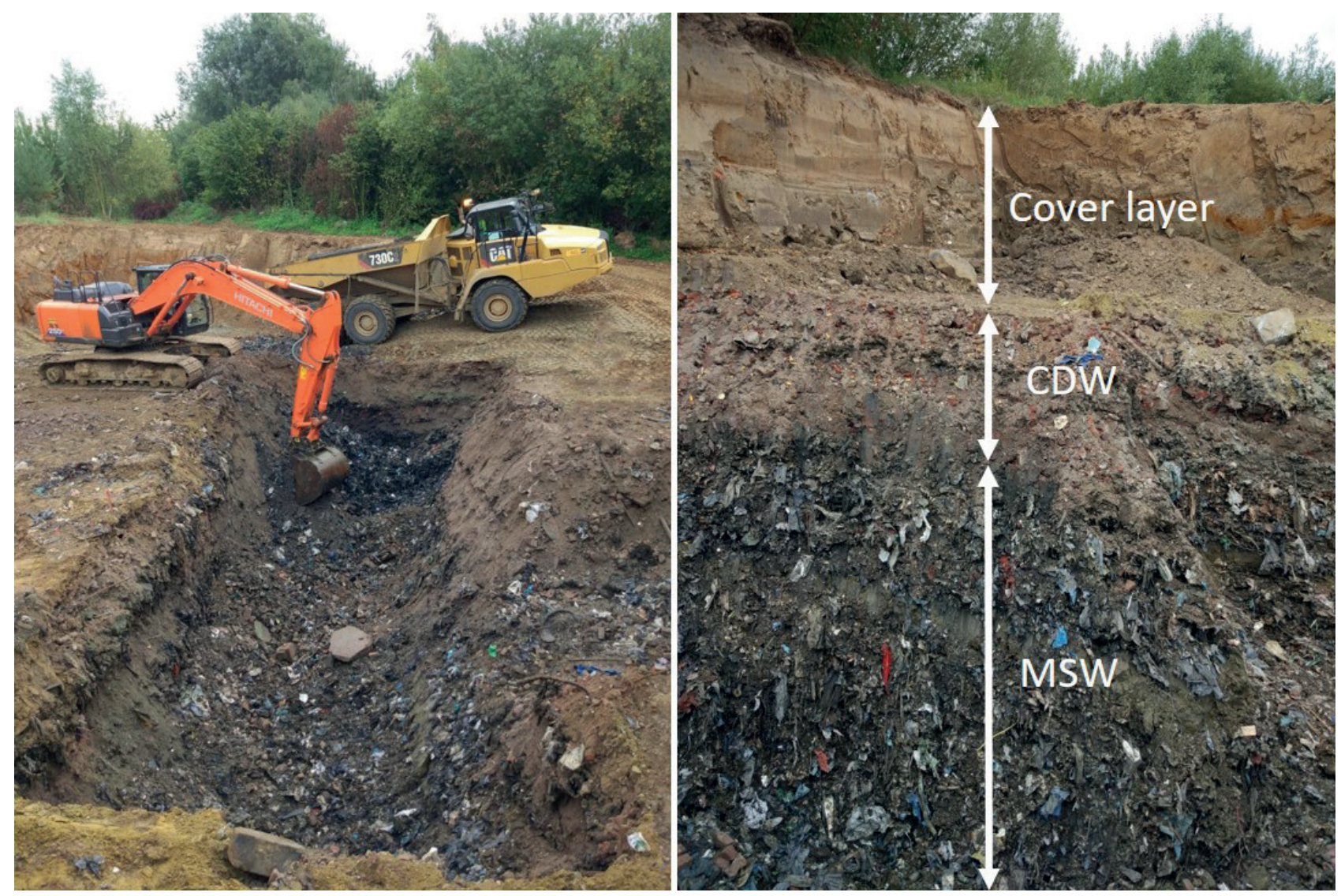

FIGURE 2: Excavation at the Mont Saint Guibert Landfill, Belgium. 


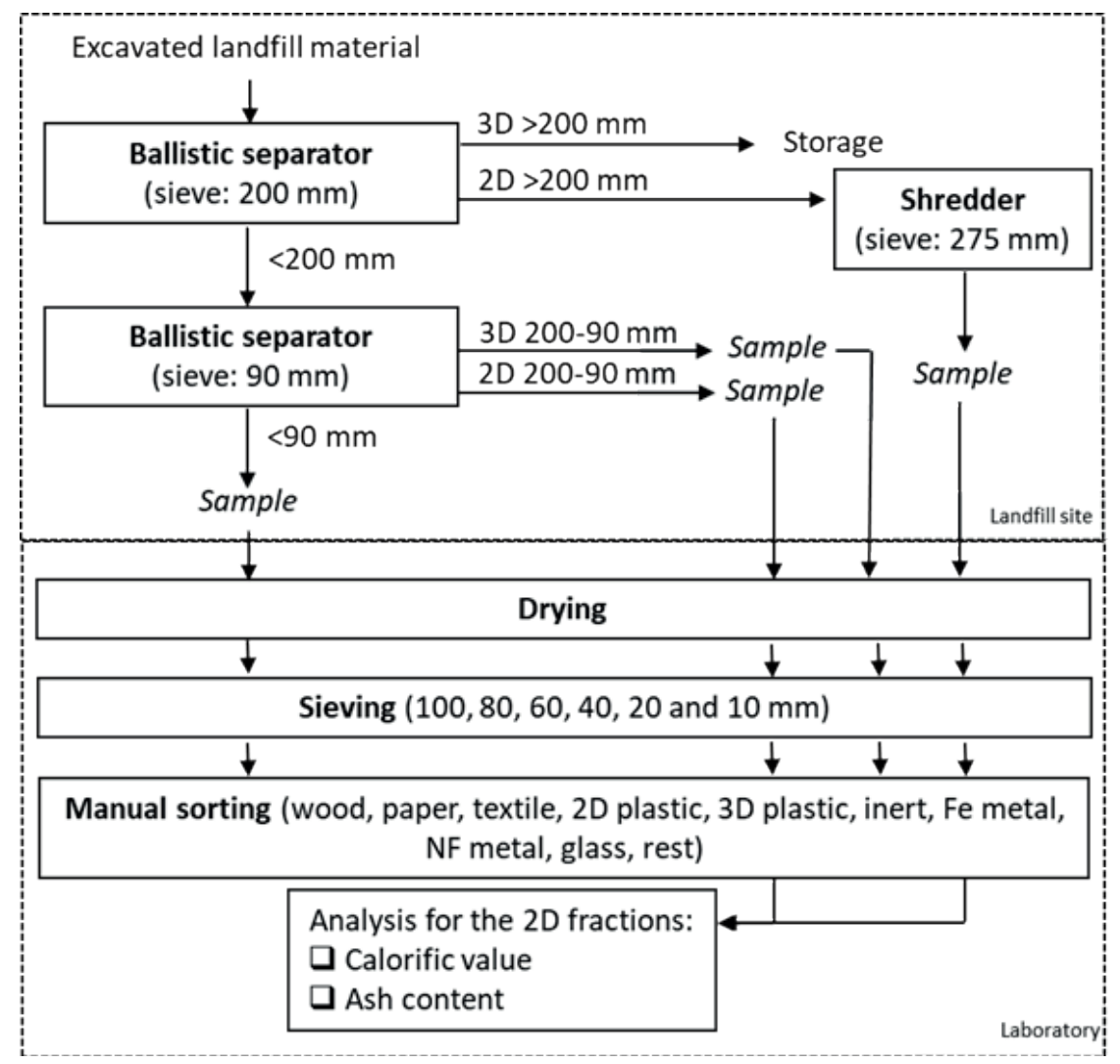

FIGURE 3: Scheme of the mechanical pretreatment, sampling campaign and methodology used in the laboratory.

The landfilled material was first sieved with a mesh size of $200 \mathrm{~mm}$ and subsequently with a mesh size of $90 \mathrm{~mm}$, as can be seen in Figure 3. The output " $2 \mathrm{D}>200 \mathrm{~mm}$ ” was fed into a shredder (sieve: $275 \mathrm{~mm}$ ) to reduce the particle size down to $<275 \mathrm{~mm}$; hereafter, this output stream is referred to as "2D <275 mm".

The sampling campaign followed the same methodology as in the case study in Halbenrain (García López et al., 2018), based on the German Directives (LAGA PN 78; LAGA PN 98). The "3D $>200$ mm" output stream was not sampled; instead, all the output material was sorted in situ into different categories (Table 1). Moreover, $60 \mathrm{~m}^{3}$ of the obtained fraction <200 $\mathrm{mm}$ were subsequently processed with the ballistic separator with a mesh size of $90 \mathrm{~mm}$, from which 3 additional output streams were obtained: 2D 200-90 mm, 3D 200-90 $\mathrm{mm}$ and $<90 \mathrm{~mm}$.

The following numbers of samples were taken exclusively during the mechanical treatment and were adapted to the time of the process to achieve the maximum level of representation: i) 2D $<275 \mathrm{~mm}, 8$ samples $(n=8)$, summing to $132 \mathrm{~kg}, \mathrm{ii}) 2 \mathrm{D} 200-90 \mathrm{~mm}, 9$ samples $(\mathrm{n}=9)$, summing to $63 \mathrm{~kg}, \mathrm{iii}) 3 \mathrm{D} 200-90 \mathrm{~mm}, 7$ samples $(\mathrm{n}=7)$,

TABLE 1: Classification of the landfilled material by categories.

\begin{tabular}{|c|c|c|}
\hline Category & Material & Age of site (as of 2018) \\
\hline 1 & Wood & All types of wood \\
\hline II & Paper & Paper, cardboard, composite carton \\
\hline III & Textile & All types of textiles \\
\hline IV & Plastic 2D & Bags, foils \\
\hline V & Plastic 3D & PP, PET, HDPE, LDPE, PVC, PS, others \\
\hline VI & Fe metals & Iron \\
\hline VII & NFe metals & Non ferrous metals: copper, aluminium, lead, others \\
\hline VIII & Inert & Mineral fraction (stones), ceramic \\
\hline IX & Glass & Colorless glass, green glass, brown glass, others \\
\hline $\mathrm{x}$ & Rest & $\begin{array}{l}\text { Rubber, foam, EPS, silicone, melted plastics, sandpaper, hazardous waste (e.g. sanitary material), unidentified, compo- } \\
\text { sites }\end{array}$ \\
\hline $\mathrm{XI}$ & Fines & Particles $<20 \mathrm{~mm}$ \\
\hline
\end{tabular}


summing to $154 \mathrm{~kg}$ and iv) <90 mm, 12 samples ( $\mathrm{n}=12)$, summing to $116 \mathrm{~kg}$. All the figures with fluctuations given in this study are based on the corresponding number of samples. The samples were further characterized in the Department of Processing and Recycling at the RWTH Aachen University.

\subsection{Characterization of landfill mining material}

\subsubsection{Moisture content and particle size distribution}

Based on the DIN CEN/TS 15414-1 all samples were dried but at a reduced temperature of $75^{\circ} \mathrm{C}$ to prevent plastics from melting, which can happen at higher temperatures.

After drying, the samples from the output streams 3D 200-90 mm, 2D 200-90 mm, <90 mm were sieved with a drum sieve and a box sieve at the Department of Processing and Recycling (RWTH Aachen University), except for the ones from $2 \mathrm{D}<275 \mathrm{~mm}$, which did not provide realistic information regarding the size of the original material. As a result, seven particle size fractions were generated: 200 $100 \mathrm{~mm}, 100-80 \mathrm{~mm}, 80-60 \mathrm{~mm}, 60-40 \mathrm{~mm}, 40-20 \mathrm{~mm}, 20-$ $10 \mathrm{~mm}$ and $<10 \mathrm{~mm}$.

\subsubsection{Material composition by output stream}

All the particle size fractions $>20 \mathrm{~mm}$ from $2 \mathrm{D}<275$ $\mathrm{mm}, 2 \mathrm{D} 200-90 \mathrm{~mm}, 3 \mathrm{D} 200-90 \mathrm{~mm}$ and $<90 \mathrm{~mm}$ were sorted manually into eleven categories, listed in Table 1. There is no category for organic waste (food scraps, green waste, etc.) because they were not distinguishable after at least 15 years inside the landfill. It is likely that the organic material was degraded to soil-like material (Quaghebeur et al., 2013). At this point, it must be mentioned that no pure and clean materials can be obtained by manual sorting without washing or using other pretreatment due to surface defilement and material agglomeration.

\subsubsection{Calorific value and ash content}

Such characteristics as calorific value, amount of organic carbon, total carbon, ash content, and hydrogen and nitrogen contents are needed to be measured to assess the efficiency for WtE applications (Quaghebeur et al., 2013). In this case, only the gross calorific value (GCV) and the ash content were determined. These values give information about the recoverable energy and amount of residue produced in the combustion process (Kuchta, Hobohm, \& Flamme, 2017). Before conducting the analysis, several mills (hammer mill, disc mill and cutting mill) were used to reduce the size of the particles down to $1 \mathrm{~mm}$. After the particle size reduction of each category in each sample, the GCV was determined according to the DIN 51900-1 and the ash content based on DIN EN 15403. The measurements were only conducted for the 2D output fractions (2D 200$90 \mathrm{~mm}$ and $2 \mathrm{D}<275 \mathrm{~mm}$ ), which were estimated to have a high heating value. Metals and glass were assumed to have a GCV of $0 \mathrm{~J} / \mathrm{kg}$ and an ash content of $100 \%$.

\section{RESULTS AND DISCUSSION}

\subsection{Moisture content and particle size distribution}

The moisture content landfilled material plays an important role when considering the material processing
(Hull et al., 2005). Previous experiences include that moisture contained in excavated waste did not impede its processability, but it might have an impact on the processing efficiency (Kaartinen et al., 2013). Drying could (i) reduce the amount of surface defilement; increase both the quality of the recyclable materials and the efficiency of sorting processes, (ii) enable a more efficient and precise particle size classification in the screening and sieving processes, (iii) decrease the total amount of material to be processed and perhaps transported and (iv) raise the calorific value (Hernández Parrodi et al., 2018a).

The fluctuations in the moisture content within the samples of every output stream are represented in Figure 4. The similar moisture contents of $2 \mathrm{D}<275 \mathrm{~mm}$ and $2 \mathrm{D}$ $200-90 \mathrm{~mm}$, with averages of $31 \%$ and $32 \%$ respectively, allow a first estimation about their composition, which is described in detail in the section "3.2. Material composition". The output " $<90 \mathrm{~mm}$ " is characterized by a slightly lower average moisture content of $28 \%$, while "3D 200-90" $\mathrm{mm}$ contains considerably less water, showing an average of $12 \%$. The latter correlates with the low capacity to hold water of materials usually found in the 3D output stream of ballistic separators, such as stones, metals, glass, rubber and wood.

It has been reported that the moisture content and amount of organic matter are interrelated and decrease with the age of the waste due to microbiological activity (Quaghebeur et al., 2013). Dating back to the 1960s and 1970s, the investigated waste from MSG can be considered as old. Nevertheless, the amount of water is still notable, with a range of $9-41 \%$, which might be explained by the thick layer of clay used as cover material and the type of waste landfilled. More permeable material, such as compost, leads to higher degradation rates and thus faster water reduction.

Due to this moisture, fine particles likely adhere to surfaces and larger particles which may lead to an increased share of the fine fraction after drying (Kaartinen et al., 2013) .Combined with the subsequent sieving, this may contribute to the reduction of surface defilement and as a consequence, compliance with the requirements for other waste treatments, e.g., sensor-based sorting if considered for further processing.

Drying the material is an operational cost but can reduce the total mass being transported and fed into the mechanical processing; hence, the throughput might be increased and transportation costs reduced. Other effects of drying are an increase in the $\mathrm{CV}$ and more effective sieving results.

Figure 5 illustrates the total mass ( $\mathrm{dm} \%$ ) by particle size $(\mathrm{mm})$ in each sieved output stream from which it can be deduced that a dried sample of landfilled material contains more fine particles than it did under humid conditions. After drying, $51 \%$ of the output stream "2D 200$90 \mathrm{~mm}$ " is smaller than $80 \mathrm{~mm}$, even though it was first classified as $>90 \mathrm{~mm}$ by the sieve of the ballistic separator. Moreover, fines $<10 \mathrm{~mm}$ in this output stream make up $30 \%$, which is almost as high as the share of particles $>100 \mathrm{~mm}$ (35\%).

For the "3D $200-90 \mathrm{~mm}$ ", $28 \%$ is $<80 \mathrm{~mm}$. This statement can only be made with some reservations, since 


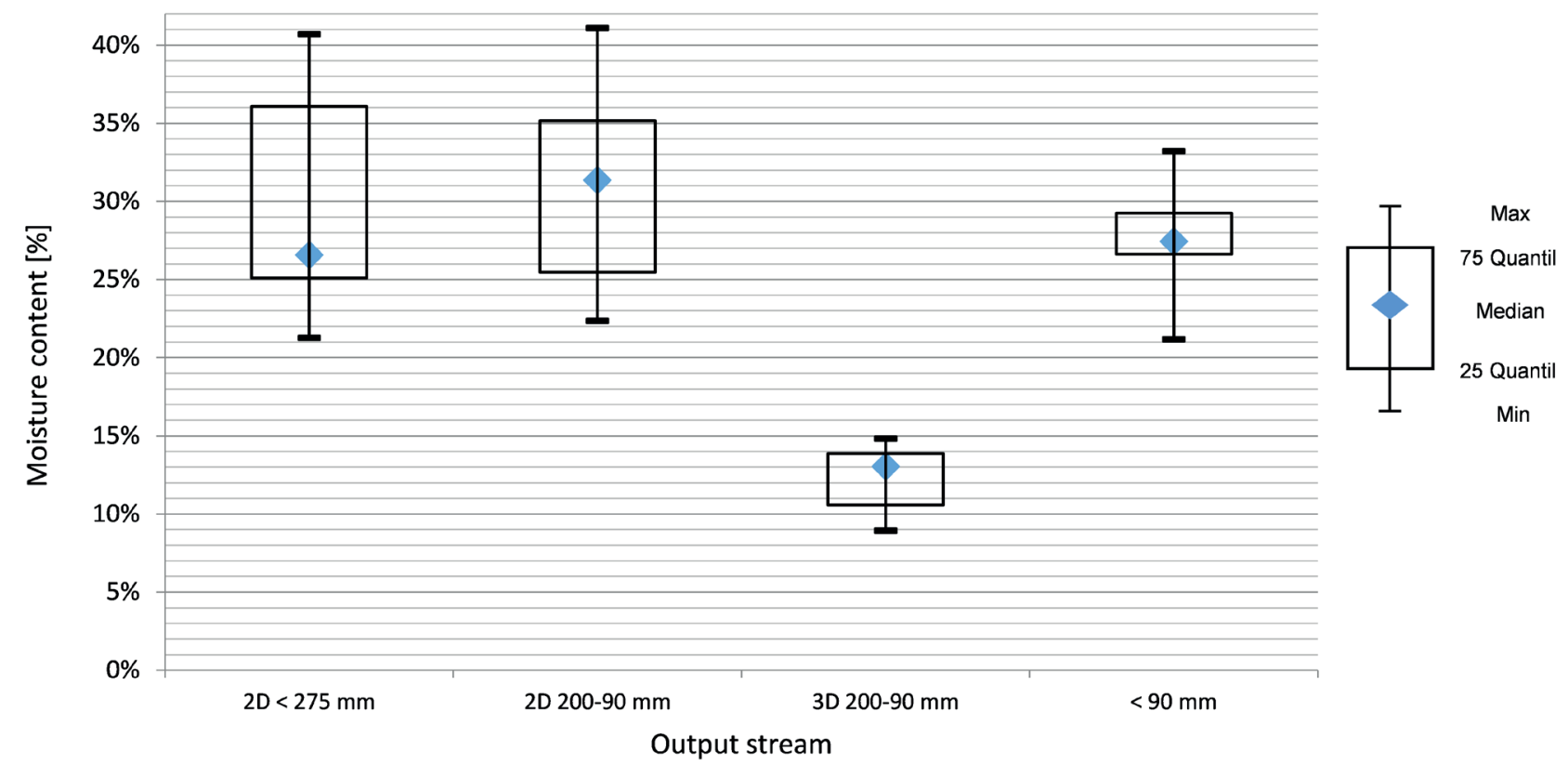

FIGURE 4: Fluctuations in the moisture content by the output stream of the ballistic separator. Number of samples shown, $n=8, n=9, n=7$, $\mathrm{n}=12$.

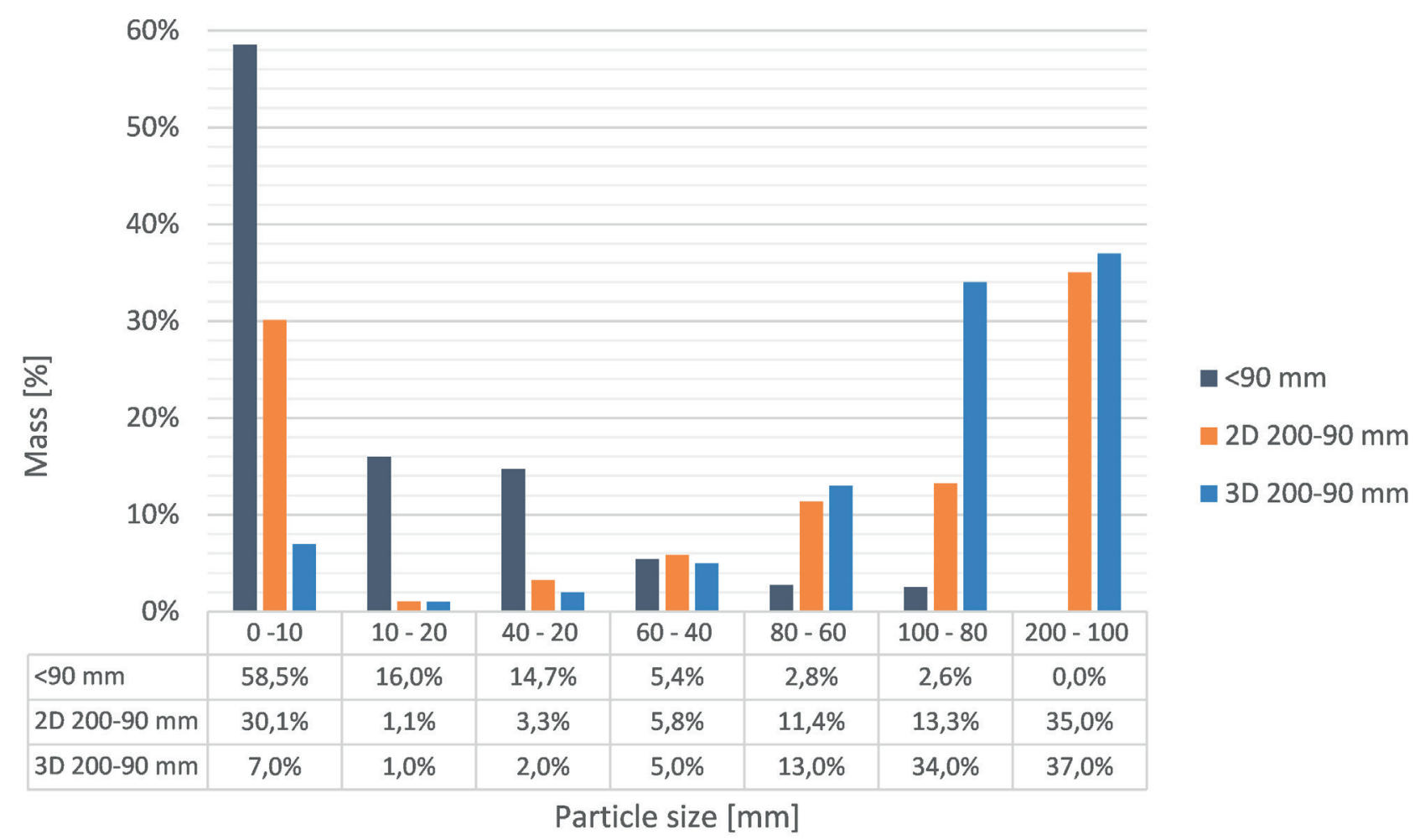

FIGURE 5: Distribution of the total mass ( $\mathrm{dm} \%$ ) by particle size in each sieved output stream of the ballistic separator STT 6000 using landfilled waste.

some bricks broke during the sieving in the drum sieve, especially in the first run with a mesh size of $100 \mathrm{~mm}$. This means that the actual throughput at particle size $100 \mathrm{~mm}$ is lower than indicated in Figure 6 and that the particle-size fraction $200-100 \mathrm{~mm}$ composes more than one third of the whole output stream "3D 200-90 mm". Besides, more fines than those originally contained in the samples are generated due to abrasion processes while sieving the material.

In addition, there is a concentration of material in the smaller particle size fractions: $34 \%$ of "2D $200-90 \mathrm{~mm}$ " is < $40 \mathrm{~mm}$ and $30 \%$ is $<10 \mathrm{~mm}$. Regarding the output stream $<90 \mathrm{~mm}$ this observation is more significant, with values of $90 \%$ and $59 \%$, respectively. 
In line with the above-described findings, the moisture content of all samples varies between 9 and $41 \%$ and on the average makes up for almost a third of the RDF potential fractions. The PSD reveals a high percentage of fine material, not only in the output stream $<90 \mathrm{~mm}$ but in all outputs due to the large amount of impurities found between the large particles, which are separated by the drying process.

\subsection{Material composition}

The excavated waste from MSG (batch 1) consisted of three main categories: inert, fines and plastics. In this study, all particles with a particle size $<20 \mathrm{~mm}$ are defined as fines. Figure 6 gives an overview of the material distribution in all the output streams generated by the ballistic separator. As expected, most fines are found in the output stream $<90 \mathrm{~mm}$, additionally both, 2D $>200 \mathrm{~mm}$ and 2D 200-90 mm, show considerable amounts of fines. Inert material is concentrated in the 3D output streams (3D >200 $\mathrm{mm}$ and 3D 200-90 mm). The ferrous metals (Fe metals) are mainly found in the 3D output streams: $3 \%$ in the $>200$ $\mathrm{mm}$ and $5 \%$ in the $200-90 \mathrm{~mm}$ output, as well as wood with $4 \%$ in the both 3D output streams. It must be noted that the mass percentages of " $3 \mathrm{D}>200 \mathrm{~mm}$ " are given on a wet matter (wm) basis, while the other streams flows refer to dry matter (dm). Detailed figures (Fig. A.1-3) with the average values of the masses by particle size in each output can be found in the Appendix.

\subsubsection{Output stream 3D 200-90 mm}

The box whisker diagram in Figure 7 illustrates that the inert fraction is by far the largest with a median of $75 \%$, while the other fractions all range below $10 \%$ with tendencies toward $0 \%$; the shares of the categories paper, textile, 2D plastics, Non Ferrous (NFe) metals and glass are less than $1 \%$. The same explanation as above may be considered for the high amount of inert material: the upper layer of the pit consisted of CDW. The second largest fraction is that of fines ( $8 \%$ ), followed by Fe metals and wood, $5 \%$ and $4 \%$ respectively. Regarding Fe metals and wood, it was observed that half of the samples contained compounds of both materials in the fractions $60-40$ and 40-20 mm. As the magnetic forces of a magnetic separator attract ferrous materials, wood parts containing nails were categorized as Fe metals. On the other hand, a large piece of wood (100-80 mm) with nails was identified and classified as wood. Another compound found was wood with 3D plastic.

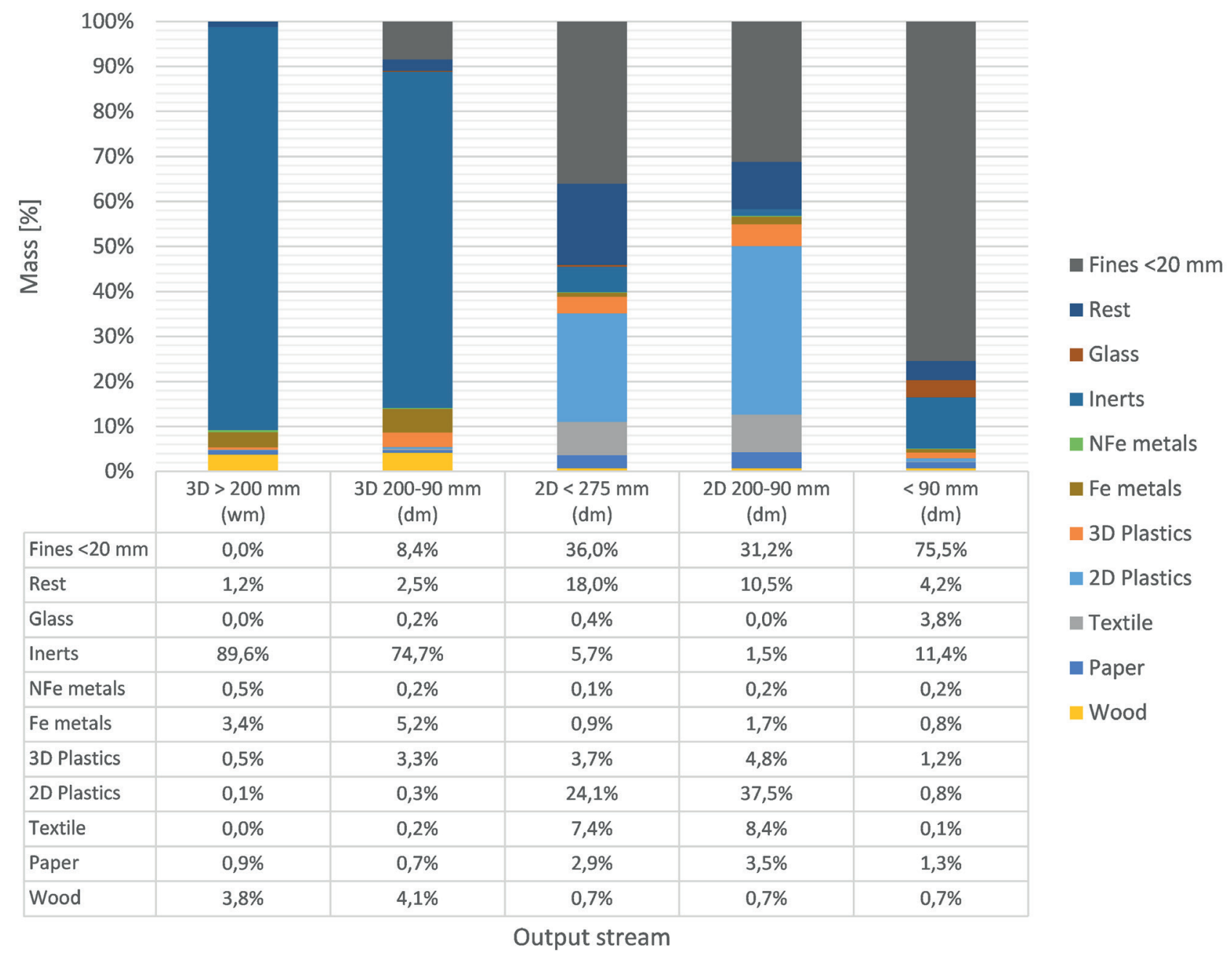

FIGURE 6: Composition of all output streams by categories. 


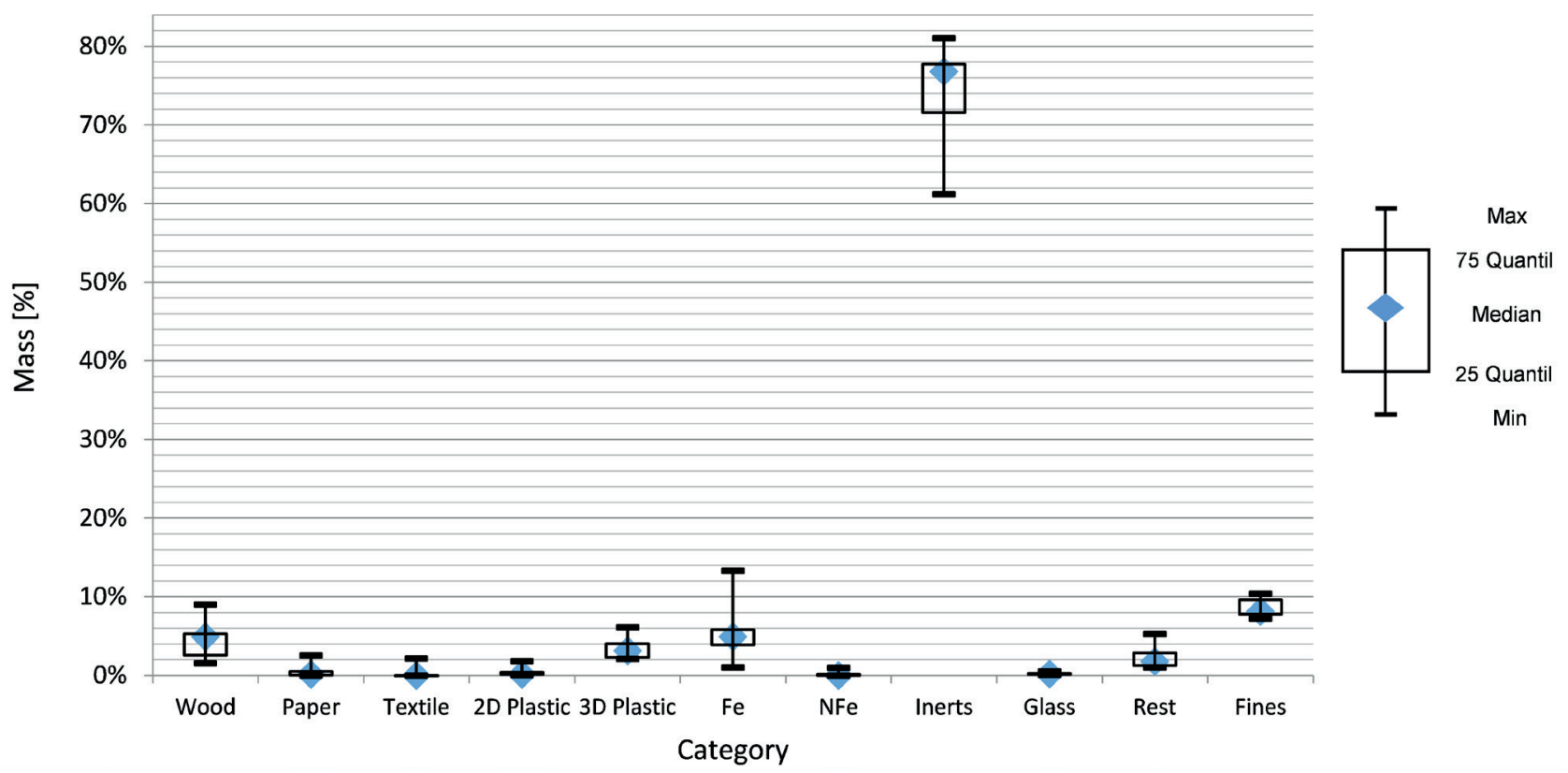

FIGURE 7: Output “3D 200-90 mm”: fluctuations in the material composition, dm \% ( $\mathrm{n}=7)$.

The fluctuations indicate that the samples do not differ strongly from each other. The largest variations are observed in the categories wood, Fe metals and inert material, which also correspond to those obtained in previous LFM investigations.

Figure 8 represents the composition of each particle size fraction indicating its weight as it relates to the total weight of the output "3D 200-90 mm". The two larger coarse fractions make up most of the material, $37 \%$ and $34 \%$, but breaking and abrasion in the drum sieve have affected the PSD distribution. Wood presented in the output "3D 200-90 $\mathrm{mm}$ " is distributed equally between the three larger particle size fractions, whereas most iron particles are counted in the $100-80 \mathrm{~mm}$ fraction (2\%). The low quantity of glass $(0.2 \%)$ might be explained by the fact that glass is likely to break and pass the sieve, both when previously transported and landfilled and during the excavation and mechanical stress in the ballistic separator, finally ending in the output stream $<90 \mathrm{~mm}$.

Looking to further processing steps, the enrichment of one material by sieving could result in difficulty due to similar distribution curves. Therefore, different sorting treatments such as magnetic separation, sensor-based separation (Beel, 2017; Martens \& Goldmann, 2016), or float-sink separation (Bauer et al., 2018; Kranzinger et al., 2017) could be considered. Generally, the composition resembles the output "3D >200 mm" although it shows an increased number of fines generated in the PSD process (particle breakage and the drying process). Hence, the ballistic separator meets the expectations for enrichment of 3D materials.

\subsubsection{Output stream $2 D<275 \mathrm{~mm}$}

As shown in Figure 9, the output stream 2D $<275 \mathrm{~mm}$ has a heterogeneous composition in comparison with $3 \mathrm{D}$ 200-90 $\mathrm{mm}$, where the fine fraction $(<20 \mathrm{~mm})$ holds the largest share with $36 \%$ of the total. These fines are mainly composed of a mix of 2D plastics and soil-like material that may have been generated during the shredding process and due to the high detention time inside the shredder (Figure 10). To prevent losing this part of the combustibles in the fine fraction, sieving with a mesh size of 10 or $5 \mathrm{~mm}$ is suggested. Moreover, a considerable number of particles (particle size approximately $<3 \mathrm{~mm}$ and smaller) were attracted by the magnet, being magnetic soil-like. Comparable findings are also described by Quaghebeur et al., 2013, where the amount of metallic iron in the magnetic fraction was between 8 and $9 \%$.

The second-largest fraction is made up by $2 \mathrm{D}$ plastics with an average share of $24 \%$, followed by Rest with $18 \%$. Many particles categorized as Rest during the sorting process are compounds, such as carpets and nappies. They are mainly made of plastic, textile and cellulose, thus this category may be considered as a highly calorific fraction. Another compound that was mainly present in the output stream "2D $<275 \mathrm{~mm}$ " consists of cables. If the 2D and 3D plastics, Rest, wood, paper and textile are considered highly calorific materials, $57 \%$ of the total mass has RDF potential. However, wood is insignificant with less than $1 \%$. The same applies to glass and both Fe and NFe metals. Metals could not be separated completely due to attached pieces of plastic, mostly two-dimensional, textile or other materials.

\subsubsection{Output stream 2D 200-90 mm}

As it can be seen in Figure 11, the grain-size fractions $>60 \mathrm{~mm}$ in the 2D 200-90 $\mathrm{mm}$ flow are especially rich in plastic foils ( $>45 \%$ ). As expected, the main component of this flow are 2D plastics with an average content of $41 \%$ (Figure 12). In contrast, 32\% were fines (<20 mm), which may reduce the RDF potential drastically. However, the categories Rest and wood could contribute to increase the 


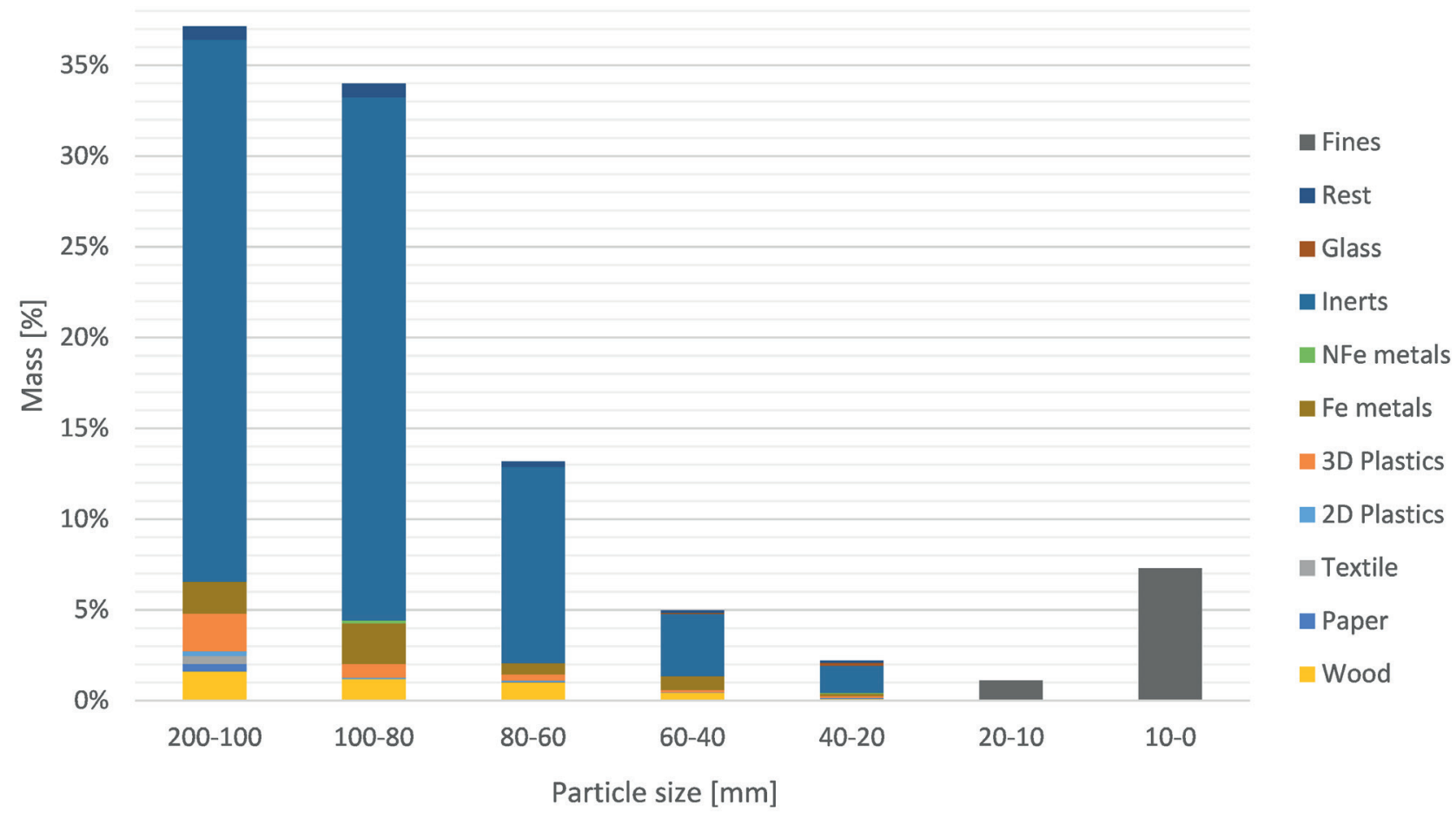

FIGURE 8: Material composition of the output stream "3D 200-90 mm" by particle size.

calorific value with a share of $7 \%$ and $6 \%$ respectively, since they are considered combustible materials.

Furthermore, it can be said that fraction $40-20 \mathrm{~mm}$ has a very heterogeneous composition consisting of all materials except glass, while the other sorted particle sizes are characterized by $2 \mathrm{D}$ plastics as the main component.

All inert material can be discharged by sieving with a mesh size of $80 \mathrm{~mm}$, as shown in Figure 15. Apart from wood and fines, all other categories show similar distribution curves, so sieving alone will not be suitable for the enrichment of single categories as it is also the case for 3D $200-90 \mathrm{~mm}$. Regarding the heterogeneous composition of both 2D streams compared to the 3D stream characterized by CDW, it can be deduced that the composition of this stream consists mainly of MSW with a high content of potential combustibles.

\subsubsection{Output stream $<90 \mathrm{~mm}$}

Most of the output stream (75\%) consisted of fines $<20$ $\mathrm{mm}$, Figures 13 and 14 . These were not sorted manually, but as a general observation the particle sizes between 20 and $10 \mathrm{~mm}$ consisted mainly of glass and those $<10 \mathrm{~mm}$ of soil-like material, comparable to the Fines of $2 \mathrm{D}<275 \mathrm{~mm}$ and 2D 200-90 mm. Within the categories (>20 mm), inert material makes up the largest part ranging between 5-23\% of the total, with an average of $14 \%$ Also worth mentioning is the amount of glass in fraction $40-20 \mathrm{~mm}(4 \%)$. Together with the glass present in fraction $20-10 \mathrm{~mm}$ this confirms the previous assumption that glass is likely to break and pass to smaller grain-size fractions.

Looking at the PSD of the materials in Figure 13, a conclusion similar to the other outputs can be made: sieving with a mesh size of $40 \mathrm{~mm}$ may yield a material stream poor in glass but further enrichment does not seem realizable with the mesh sizes used in the analysis.

\subsubsection{Overview of all output stream}

Normally the 3D output streams of ballistic separators used to separate fresh waste contain stones, metals, glass, rubber and wood ( $\mathrm{H}$. Martens, 2016). In comparison, the results of the present paper show that the same applies for landfilled CDW and MSW with one exception: glass is only present in the finer fraction of the output stream $<90$ $\mathrm{mm}$. Thus, considering the enrichment of highly calorific materials in the 2D streams, mostly 2D plastics, the ballistic separator seems to meet the expectations.

Nevertheless, a mass balance of the whole process must be considered to estimate a reliable potential for the whole landfill. This means that the composition of every output stream must be related to its share in the total flow when extrapolating the absolute mass of all materials stored in the landfill. Figure 15 presents the mass balance considering wet and dried material. However, the total water content must be higher than the indicated $25 \%$ because the moisture content of the output " $3 \mathrm{D}>200 \mathrm{~mm}$ " was not analysed in this study and the water is evaporated during separation. Nevertheless, it points out the high share of particles in the output stream $<90 \mathrm{~mm}, 58 \%$ of the input material, compared to $4 \%$ (dry) with RDF potential from which the fines separated by sieving must still be subtracted. Two main reasons are considered for the predominant share of fines: the longer the waste is stored, the more organic material can be degraded; thus, the amount of fines increases with time (Maul et al., 2016). Besides, the cover layer is a source of fines because usually soil is used as a daily cover (Kaartinen et al., 2013). 


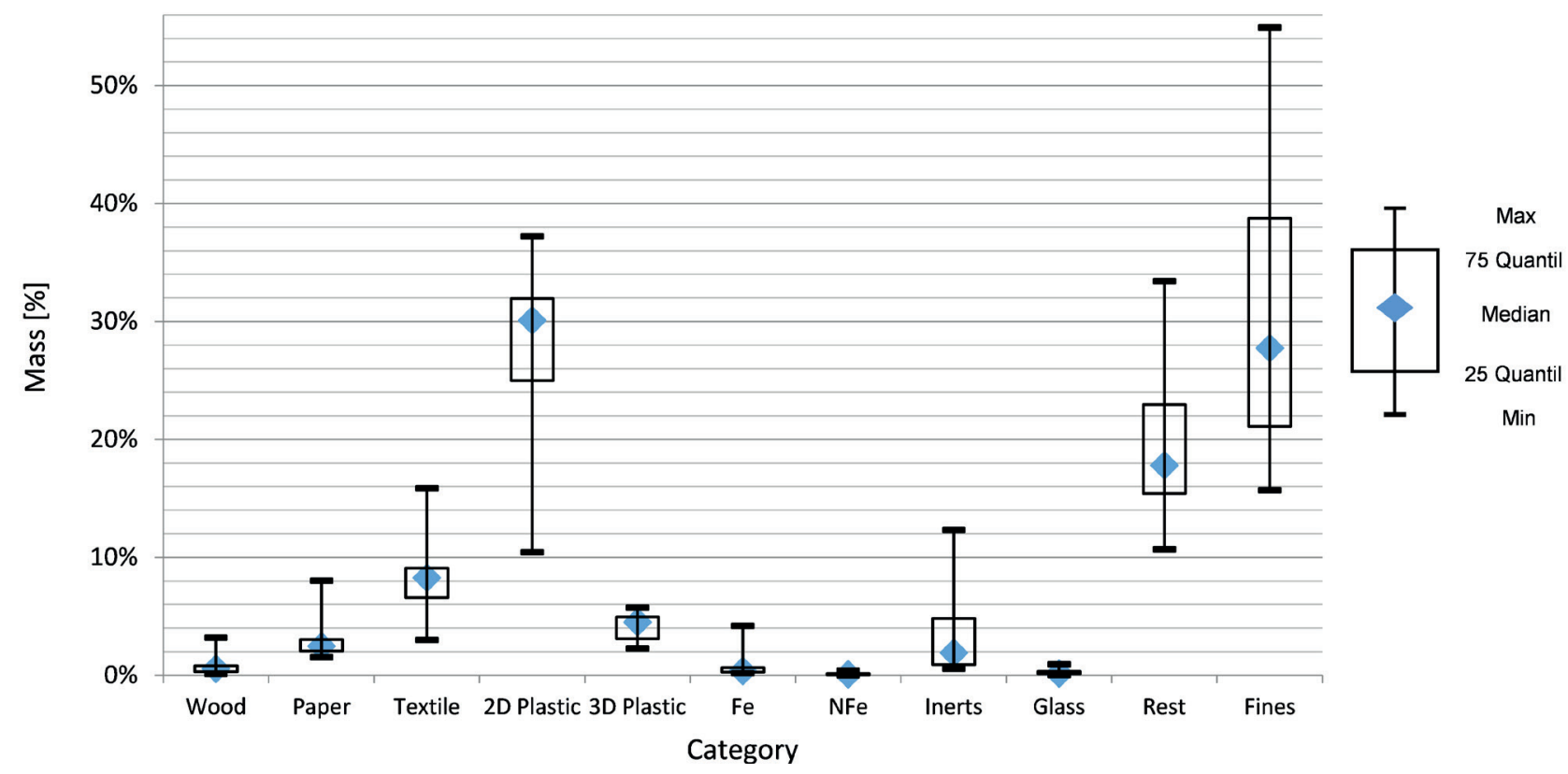

FIGURE 9: Output "2D <275 mm: fluctuations in the material composition, dm \% ( $n=8)$.

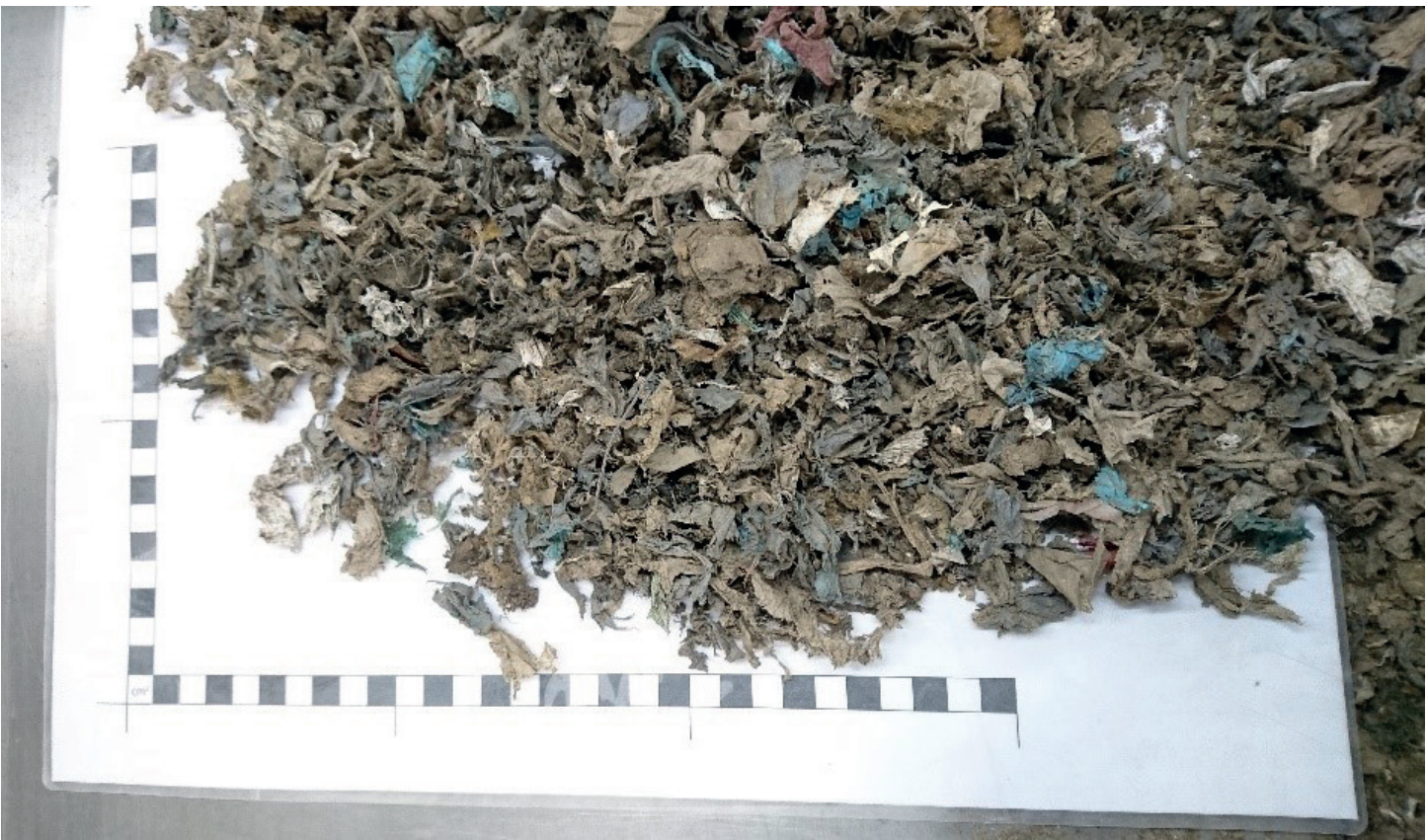

FIGURE 10: Fines $(<20 \mathrm{~mm})$ from the output stream "2D $<275 \mathrm{~mm}$ ".

\subsection{Calorific value and ash content}

In order to assess the quality of the potential RDF produced by the ballistic separator, Table 2 shows the distribution of the calorific values, the ash content and the mass percentages by material categories in both 2D output stream, 2D <275 $\mathrm{mm}$ and 2D 200-90 mm.

As expected, 2D plastic, with a considerable share of the output streams, is the material with the highest calorific value, 35.1 and $40.9 \mathrm{MJ} \mathrm{kg}^{-1}$, followed by the 3D plastics with an average of 32.4 and $30.6 \mathrm{MJ} \mathrm{kg} 1$. In the case of the Rest, the values are 18.5 and $23.3 \mathrm{MJ} \mathrm{kg}-1$, which reinforce the previous assumption that this category can be regarded as a highly calorific fraction. Compared to the mean net calorific value of $21.9 \mathrm{MJ} \mathrm{kg-1}$ (dry and ash free) for RDF (Phyllis database, 2018), the results of this study range within the same magnitude at 16.0 and 22.4 MJ $\mathrm{kg}^{-1}$. Nevertheless, the influence of the fines is significant since they make up a third of the mass. This means that by separating fines from the stream before combustion, the amount of energy produced could be increased and the ash content could be reduced. In addition, only materials with ash contents $<60 \%$ can burn autonomously (Seifert \& Vehlow, 2017). In this regard, the 2D output streams have an ash content average of 50.5 and 40.4 , thereby meet- 


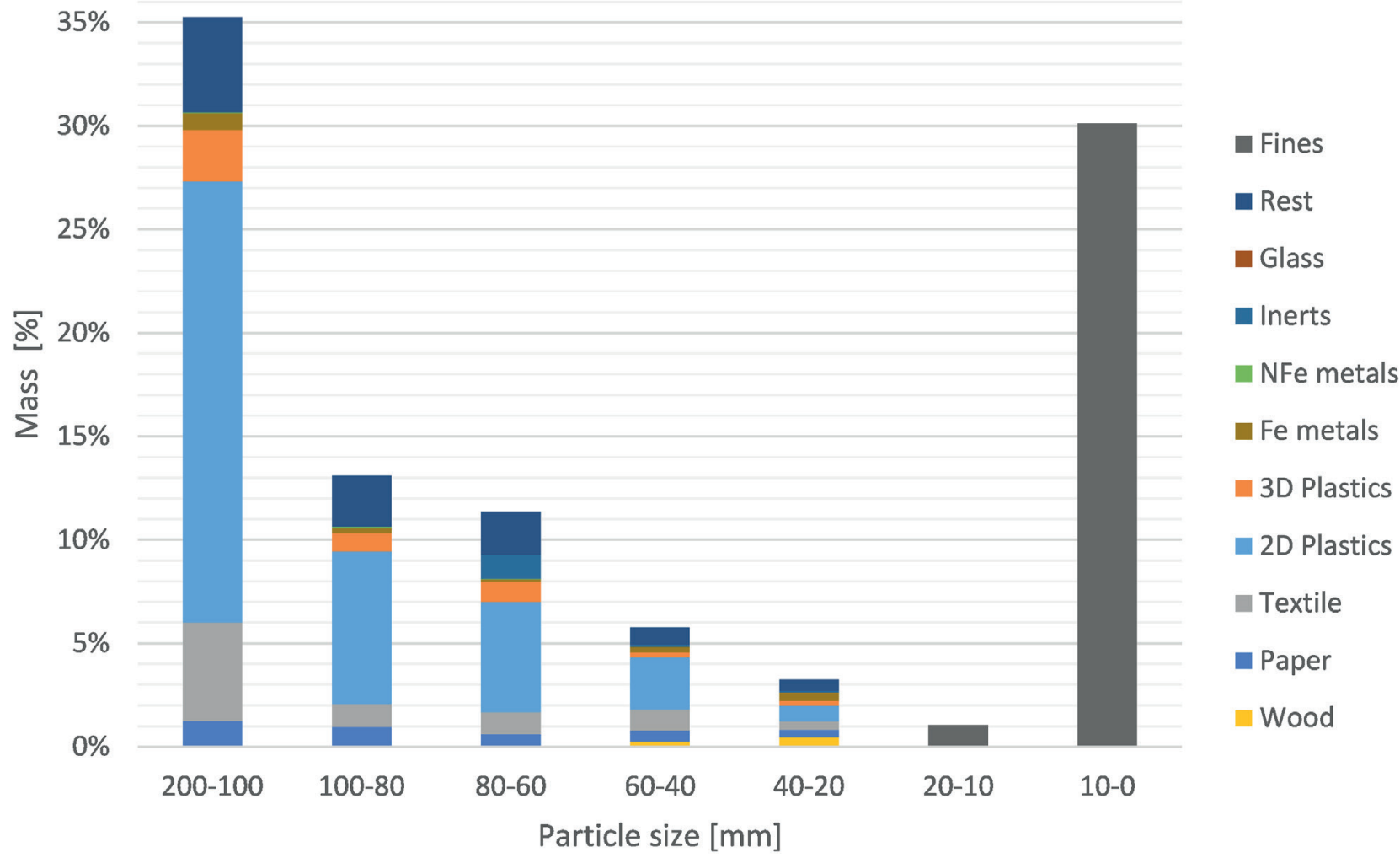

FIGURE 11: Material composition of the output stream "2D 200-90 mm" by particle size.

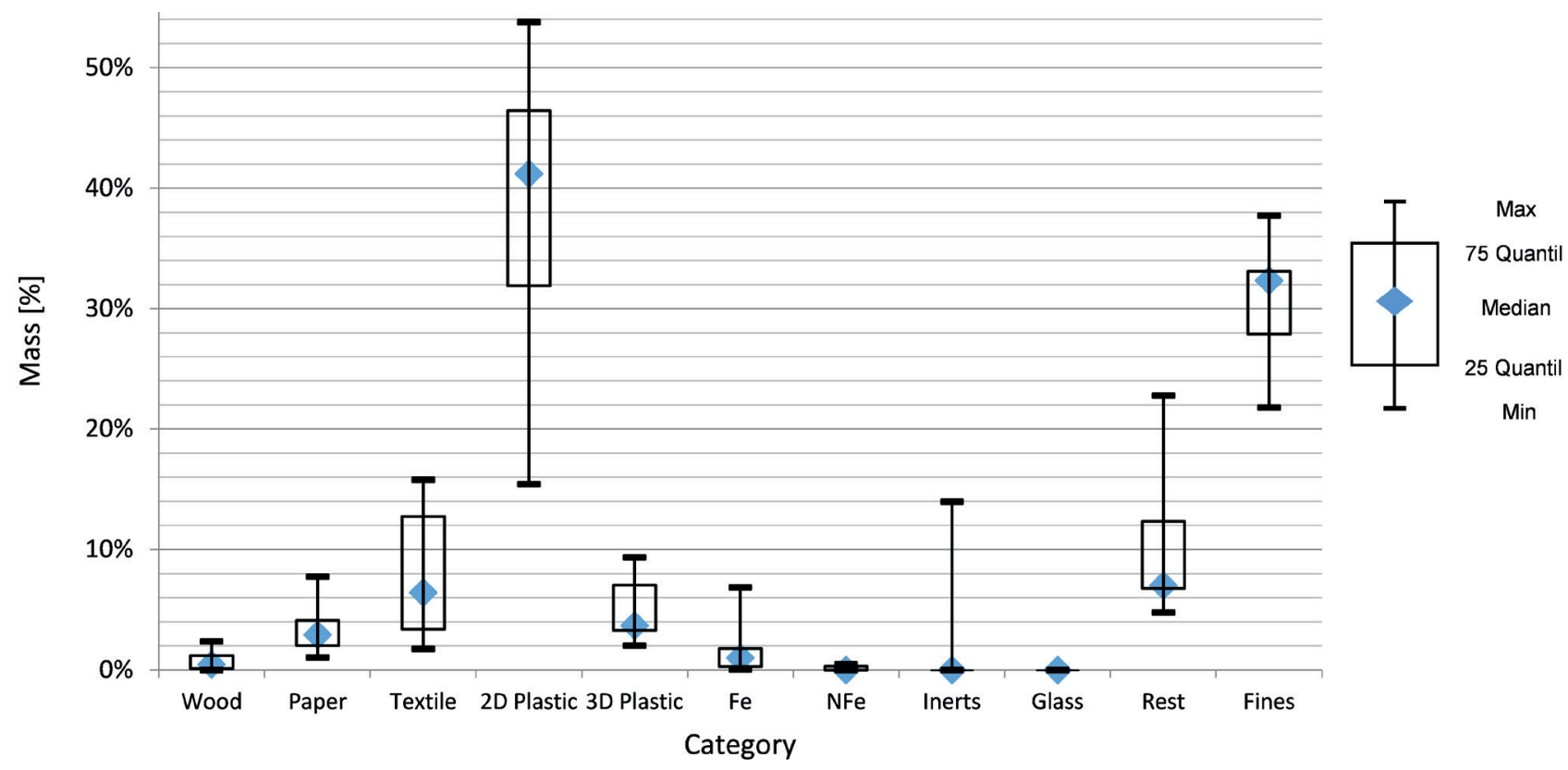

FIGURE 12: Output "2D 200-90 mm": fluctuations in the material composition, $\mathrm{dm} \%(\mathrm{n}=9)$.

ing this requirement. Moreover, low ash contents are also desirable to reduce the dust loading. It can be deduced from the low amount of materials that are not suitable for RDF (metals, inert and glass) and thus degrade the burning parameters, that the ballistic separator enriches RDF potential materials in the $2 \mathrm{D}$ stream as expected since the downgrading fines come from the surface of the RDF par- ticles and were generated in the subsequent drying process.

\subsection{Comparison with previous LFM investigations}

The total range of moisture content was between 9 and $41 \%$, comparable with data in the literature of 18 to $40 \%$ for 17 to 40 year old waste (Hernández Parrodi, 2018a), 


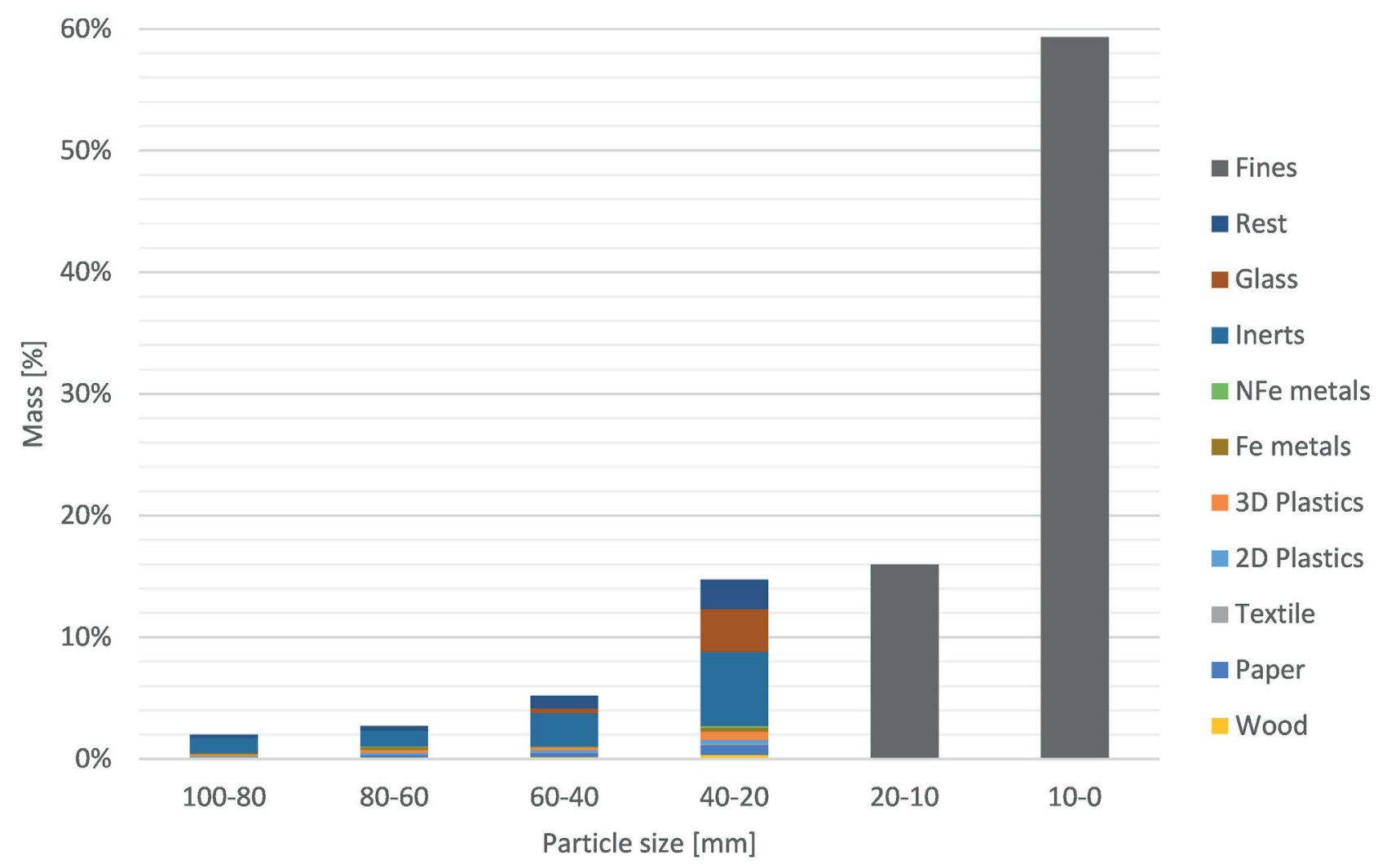

FIGURE 13: Material composition of the output stream " $<90 \mathrm{~mm}$ " by particle size.

even if data from "3D $>200 \mathrm{~mm}$ " is missing for a complete comparison. Apart from the age, other important parameters can influence the water content of the material, e.g., geographical location, landfill layering (water permeability), particle size and the type of waste landfilled.

The characteristics of the mined material depend strongly on the type of waste that was initially landfilled. This becomes evident when looking at the material composition indicated on a wet and mass basis from previous studies (Bhatnagar et al., 2017; Jani et al., 2016; Kaartinen et al., 2013; Quaghebeur et al., 2013; Van Vossen \& Prent, 2011; Wolfsberger et al., 2015b). In Table 3, the inert fraction ( $17 \%$ in this study) makes up more of the total when CDW was deposited. Municipal landfills, on the other hand, are characterized by $10 \%$ of inorganic substance (concrete, stones, and glass), $20-30 \%$ highly calorific fraction and $27-$ $54 \%$ soil-like materials. Thus, the share of plastics in MSW is considerably higher than the $3 \%$ found for mixed waste in this paper. The same holds for household waste materials, such as paper and textiles: the percentages counted are below the values reported in the literature $(0.4 \%$ and $2-7 \%$, respectively). With a share of approximately $46 \%$, the fines $(<20 \mathrm{~mm})$ are in accordance with MSW but different particle sizes are used to define the fines or soil-like materials. The metal concentrations in most LFM projects range below $5 \%$, nevertheless the $1 \%$ found seems low because more metals are expected from CDW, especially structural steel.

Similar to the difficulty encountered when comparing PSD, materials are classified into different categories by different researchers, especially overlapping categories (e.g., for plastics and metals) making comparison more challenging. Moreover, the efficiency of sorting, and therefore the results of the composition, depends on the applied technique: manual, mechanical or sensor-based sorting.

Findings on the GCV and ash content are compared to results presented by Quaghebeur et. al., 2013 for the REMO landfill site in Belgium. It stands out that the calorific value of the main combustible fraction (2D plastics, 35.1 and $40.9 \mathrm{MJ} \mathrm{kg}^{-1)}$ is considerably higher than for plastics analysed by Quaghebeur et. al., 2013 (19.0-28.0 MJ $\mathrm{kg}^{-1}$ ) with an ash content of $20-35 \%$ compared to $21,7 \%$ and $12,8 \%$ ( $12,8 \%$ and $11,8 \%$ for 3D plastics), depending on the $2 \mathrm{D}$ output stream in this study. Similar differences are noted for the ash content of paper and cardboard, which amounts to $25-61 \%$ at the REMO site but is only estimated to be $12 \%$ in this study. The CV of paper and cardboard is more conformable in both studies: 6.7-12.0 $\mathrm{MJ} \mathrm{kg}^{-1}$ and $15 \mathrm{MJ} \mathrm{kg}^{-1}$, respectively. The results for fines are in accordance with the compared data in which a CV of 1.3-4.8 MJ kg-1and ash contents of $64.4-87.5 \%$ are reported.

Summarizing the above comparison, it can be said that the mixture of CDW in the examined material with MSW influences the RDF potential negatively because MSW landfills are found to consist of more combustible materials. The high amount of fines described in most LFM projects is similar, whereas the $\mathrm{CV}$ and ash content are restricted in their resemblance. Standardized or widely agreed-on 


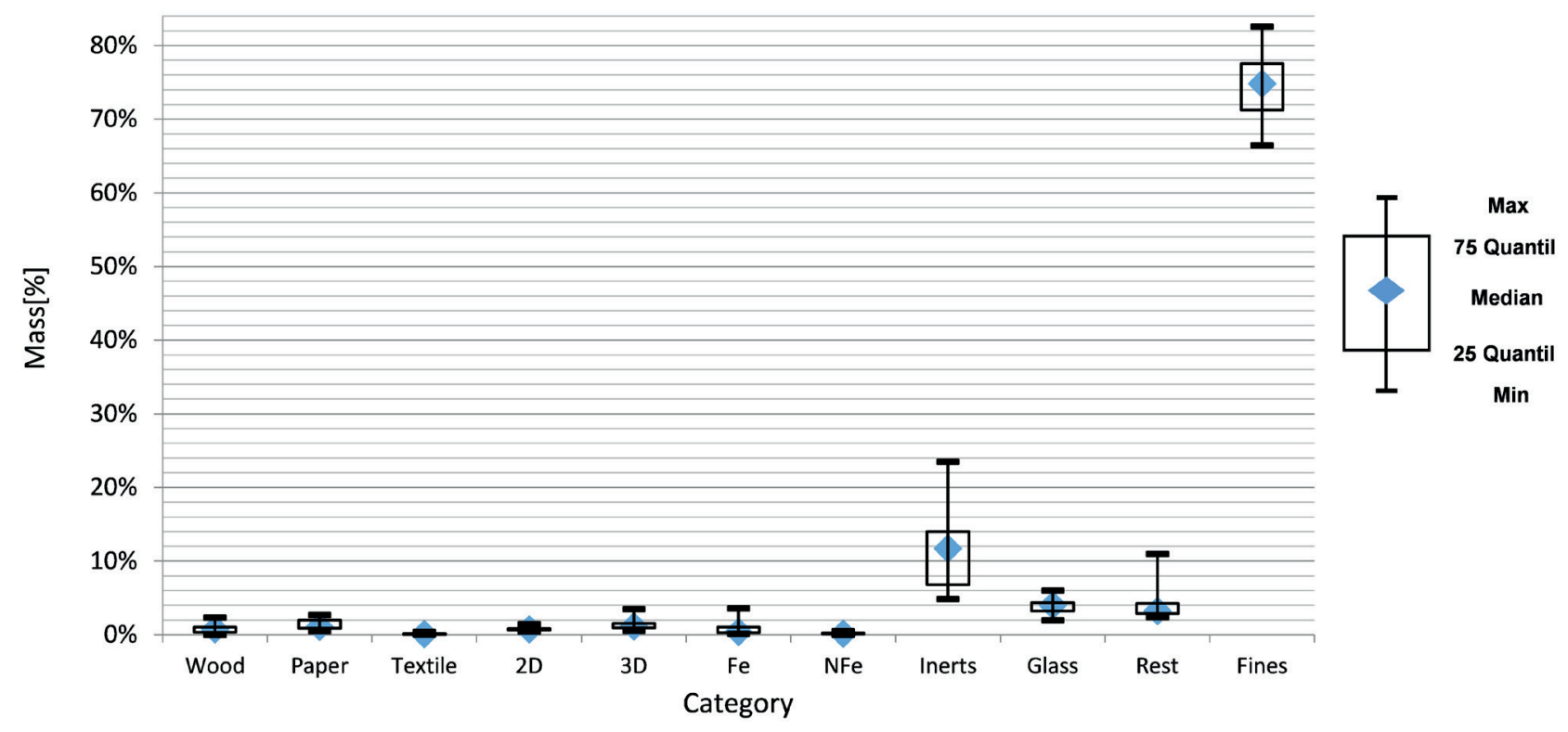

FIGURE 14: Output "<90 mm": fluctuations in the material composition, $\mathrm{dm} \%(\mathrm{n}=12)$.

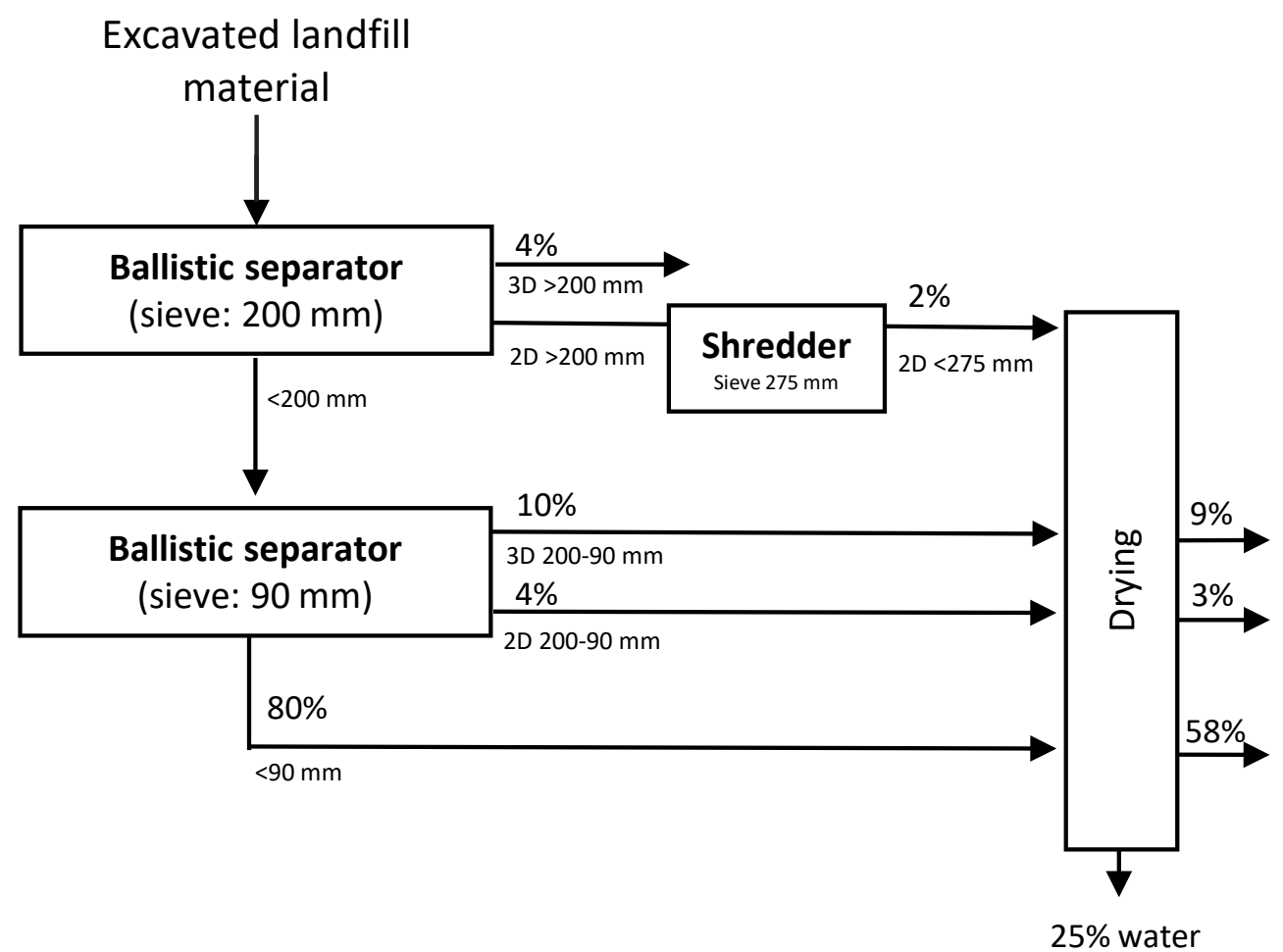

FIGURE 15: Mass balance of the ballistic separator with the two sieving steps of $200 \mathrm{~mm}$ and $90 \mathrm{~mm}$ (all indications refer to the input $100 \%)$.

material categories and particle size fractions to increase comparability are desirable.

\subsection{Recovery options}

Generally, two different recovery processes can be distinguished: WtM, which creates new materials according to the properties of the recovered materials and $\mathrm{WtE}$, which can substitute for the use of fossil fuels. For fresh plastic waste both recovery options are practised. WtM (for plas- tics) is subdivided into primary recycling without modifications of the polymers, secondary recycling with downgrading and tertiary recycling with depolymerization reactions. Primary and secondary recycling requires high-quality incoming waste. Moreover, the possibility of meeting the limits on heavy metal content must be questioned, taking into account the diverse additives that were used in the past for plastic production. Tertiary recycling seems suitable for landfill-mined plastics but only a few industrial 
TABLE 2: Average composition, GCV and ash content of the 2D <275 mm and 2D 200-90 mm output streams ( $\mathrm{m}=8$, $\mathrm{n}=9$, respectively). Data from the REMO landfill (Quaghebeur et al., 2013) were used to compare the results.

\begin{tabular}{|c|c|c|c|c|c|c|c|c|}
\hline \multirow{3}{*}{ Categories } & \multicolumn{3}{|c|}{$2 \mathrm{D}<275 \mathrm{~mm}$} & \multicolumn{3}{|c|}{ 2D 200-90 mm } & \multicolumn{2}{|c|}{ REMO, Belgium (2013) } \\
\hline & Mass & GCV & Ash content & Mass & GCV & Ash content & GCV & Ash content \\
\hline & [\% of total] & [MJ/kg] & [\%] & [\% of total] & [MJ/kg] & [\%] & [MJ/kg] & [\%] \\
\hline Wood & 0,7 & 15,2 & 10,3 & 0,7 & 16,9 & 10,9 & - & - \\
\hline Paper & 2,9 & 16,0 & 22,0 & 3,5 & 15,2 & 12 & $7.3-13.0$ & $25.0-61.0$ \\
\hline Textile & 7,4 & 22,5 & 32,0 & 8,4 & 22,7 & 19,6 & - & - \\
\hline 2D Plastics & 24,1 & 35,1 & 21,7 & 37,5 & 40,9 & 13,5 & $19.0-28.0$ & $20.0-35.0$ \\
\hline 3D Plastics & 3,7 & 32,4 & 12,8 & 4,8 & 30,6 & 11,8 & & \\
\hline Fe metals & 0,9 & - & 100,0 & 1,7 & - & 100 & - & - \\
\hline NFe metals & 0,1 & - & 100,0 & 0,2 & - & - & - & - \\
\hline Inert & 5,7 & 0,1 & 98,4 & 1,5 & - & 99,6 & - & - \\
\hline Glass & 0,4 & - & 100,0 & 0,0 & - & - & - & - \\
\hline Rest & 18,0 & 18,5 & 34,7 & 10,5 & 23,3 & 16,8 & - & - \\
\hline Fines & 36,1 & 2,0 & 79,0 & 31,2 & 1,9 & 88 & $2.1-5.7$ & $64.4-87.5$ \\
\hline Total & 100,0 & 16,0 & 50,5 & 100,00 & 22,4 & 40,4 & - & - \\
\hline
\end{tabular}

plants applying this process exist in Europe (Quaghebeur et al., 2013). Likewise, the heterogeneity and high level of contamination of paper, textiles and wood would require extensive and expensive treatment for WtM valorisation of those materials. As mentioned above, the Rest of the "2D 200-90 and 2D <275 mm" also appears suitable for WtE. Hence, for most excavated materials WtE valorisation as "Solid recovered fuels (SRF) is the most realistic marketable material" (Bhatnagar et al., 2017). RDF differs from SRF in that the latter guarantees a certain quality of the fuel, since SRF must be produced from non-hazardous waste and fulfil certain fuel qualities (Rotter et al., 2011). Therefore, more parameters, apart from the characteristics presented in this study, are needed to evaluate the efficiency and quality of the RDF generated from landfilled materials and the emissions of the combustion process. Those parameters are the amount of organic carbon, total carbon, hydrogen, nitrogen, sulfur, chlorine, fluorine, bromine and heavy metals (Quaghebeur et al., 2013). It is obligatory to indicate the concentration of chlorine according to the specification DIN EN 15359 due to its corrosive impact and the property of mobilizing some of the metals into the flue gas (Kaartinen et al., 2013). Heavy metals are of special concern for SRF made from pretreated waste (Wolfsberger et al., 2015a). Therefore, information should be gathered about the history and origin of the landfilled waste. The requirements that the above parameters must meet depend on the combustion system used and on applicable laws and authorization procedures (Kuchta et al., 2017).

If metals are not separated during the SRF/RDF production process and are directly valorised as WtM, they can be recovered from the ash after incineration (Seifert \& Vehlow, 2017). As glass is an inert material, WtM is considered for its valorisation providing an efficient separation (Quaghe- beur et al., 2013).

Of major importance is the recoverability of the fine fractions, as they make up around half of the total material excavated and have been found to be challenging in previous investigations (Hernández Parrodi et al., 2018; Jones et al., 2013). A WtE application of the fine fractions, as described by Quaghebeur et. al., 2013, is not considered to be applicable for the present material because of the age of the waste, the resulting high degree of degradation, the low CV and the high ash content. Thus, WtM options are to be considered.

One possibility is the use of the fine fractions as a cover layer in operating landfills. At the Kudjape landfill, Estonia, the fine fraction was used as a methane degradation layer. This valorisation requires a low degree of contamination (Bhatnagar et al., 2017). The use of fines and conditioned inert materials as filler and construction material generally can be considered if they comply with the limit values for such activities (Quaghebeur et al., 2013).

Heavy metals are especially expected to be found in old landfills and can contribute to decrease the costs of ELFM if recovered (Garcia Lopez et al., 2018). From these findings, the recovery of the major and trace metals from the fine fractions could be an option to meet the globally increasing demand. Conducting leaching tests and XRF analysis can give a more precise composition determination and allow an estimation of the marketable potential. Apart from the potential economic benefit of heavy metals recovery from the fine fractions, another positive effect can be the resulting reduction of their uncontrolled leaching out of the landfill (Hernández Parrodi et al., 2018; Bhatnagar et al., 2017; Quaghebeur et al., 2013; Kaartinen et al., 2013).

A third option would be to re-landfill the fine fractions, but this procedure bears costs instead of revenues and 
TABLE 3: Comparison of the material composition of this study with previous LFM investigations, adapted from Hernández Parrodi, $2018 \mathrm{.}$

\begin{tabular}{|c|c|c|c|c|c|c|c|}
\hline Type of information & $\begin{array}{l}\text { This study, } \\
2018 \text { (MSG, } \\
\text { Belgium) }\end{array}$ & $\begin{array}{l}\text { Various } \\
\text { countries } \\
\text { (Van Vossen } \\
\text { and Prent, } \\
\text { 2011) }\end{array}$ & $\begin{array}{l}\text { Högbytorp, } \\
\text { Sweden } \\
\text { (Jani et al., } \\
\text { 2016) }\end{array}$ & $\begin{array}{l}\text { Kuopio, Fin- } \\
\quad \text { land } \\
\text { (Kaartinen et } \\
\text { al., 2013) }\end{array}$ & $\begin{array}{l}\text { Kudjape, } \\
\text { Estonia } \\
\text { (Bhatnagar et } \\
\text { al., 2017) }\end{array}$ & $\begin{array}{c}\text { Lower Austria, } \\
\text { Austria } \\
\text { (Wolfsberger } \\
\text { et al., 2015) }\end{array}$ & $\begin{array}{c}\text { Houthalen, } \\
\text { Belgium } \\
\text { (Quaghebeur } \\
\text { et al., 2013) }\end{array}$ \\
\hline Type of waste & $M S W+C \& D$ & Various & $M S W+C \& D$ & MSW & MSW & MSW & MSW \\
\hline Age of waste [y] & $40-50$ & Various & 5 & $5-10$ & 10 & $13-20$ & $14-29$ \\
\hline Average moisture content & $25 \%$ & - & - & - & - & $29-55 \%$ & $48-66 \%$ \\
\hline Fines/ Soil-like material & $46 \%$ & $55 \%$ & $27 \%$ & $50-54 \%$ & $29 \%$ & $47 \%$ & $44 \%(12)$ \\
\hline Stones & - & $3 \%$ & $28 \%$ & - & $18 \%$ & - & - \\
\hline Inert/minerals & $17 \%$ & $6 \%$ & - & - & - & $6 \%$ & $10 \%(6)$ \\
\hline C\&D & - & $9 \%$ & - & - & - & - & - \\
\hline Limestone & - & - & $5 \%$ & - & - & - & - \\
\hline Asphalt & - & - & $3 \%$ & - & - & - & - \\
\hline Glass/ceramics & $2 \%$ & $1 \%$ & $6 \%$ & - & $5 \%$ & $1 \%$ & $1.3 \%(0.8)$ \\
\hline Plastics (3D/2D) & $3 \%$ & $5 \%$ & - & $23 \%$ & $22 \%$ & $18 \%$ & $17 \%(10)$ \\
\hline Soft plastics & - & - & $1 \%$ & - & - & - & - \\
\hline 2D plastics & $2 \%$ & - & - & - & - & - & - \\
\hline 3D plastics & $1 \%$ & - & - & - & - & - & - \\
\hline Other plastic/ Composites & - & - & $7 \%$ & - & - & $4 \%$ & - \\
\hline Organic/kitchen waste & - & $5 \%$ & - & - & - & - & - \\
\hline Paper/cardboard/ PPC & $1 \%$ & $5 \%$ & - & $4-8 \%$ & $5 \%$ & $3 \%$ & $7.5 \%(6)$ \\
\hline Paper & $<1 \%$ & - & $4 \%$ & - & - & - & - \\
\hline Wood & $1 \%$ & $4 \%$ & $15 \%$ & $6-7 \%$ & $5 \%$ & - & $6.7 \%(5)$ \\
\hline Textile & $<1 \%$ & $2 \%$ & $3 \%$ & $7 \%$ & - & $6 \%$ & $6.8 \%(6)$ \\
\hline Leather & - & $2 \%$ & - & - & - & - & - \\
\hline Rubber & - & - & $0 \%$ & - & - & - & - \\
\hline Wood/leather/rubber & - & - & - & - & - & $9 \%$ & - \\
\hline Total metals & $1 \%$ & $2 \%$ & - & $3-4 \%$ & $3 \%$ & $5 \%$ & $2.8 \%(1)$ \\
\hline Fe metals & $1 \%$ & - & $0 \%$ & - & - & - & - \\
\hline NFe metals & $<1 \%$ & - & $0 \%$ & - & - & - & - \\
\hline Other/ Rest & $3 \%$ & $3 \%$ & - & $2 \%$ & $13 \%$ & $1 \%$ & - \\
\hline Non-MSW & - & $0 \%$ & - & - & - & - & - \\
\hline
\end{tabular}

is not in line with the introduced goals of ELFM projects (Kaartinen et al., 2013).

Independently of the recovery option chosen for the fine fractions, their separation from other excavated materials by sieving can be essential for further processing, since it raises the purity and CV of the RDF stream and improves the possible efficiency of sensor-based sorting techniques (Hernández Parrodi et al., 2018; Maul et al., 2016). Moreover, the bulk density of the material is a very relevant parameter for the design of the mechanical treatment. Although no quantitative statement was done in this analysis, it can be said that landfilled material presents higher bulk densities than fresh MSW, since the landfill-mined material showed more fine material than those typical of MSW.

\section{CONCLUSIONS}

This study found that the 3D-output streams $(>200$ $\mathrm{mm}$ and $200-90 \mathrm{~mm}$ ) of the ballistic separator consisted mainly of coarse CDW, whereas more heterogeneous MSW was yielded in the 2D-output streams $(>200 \mathrm{~mm}$ and $200-$ $90 \mathrm{~mm}$ ). By comparing $57 \%$ of the combustible materials (plastics, paper, textiles, leather and wood) in the output "2D <275 mm" and $65 \%$ in "2D $200-90 \mathrm{~mm}$ " to $75 \%$ of inert material in "3D 200-90 mm", the efficiency of the separating process was suitable for the landfilled material. The 2D-output streams were characterized by a higher moisture content (average, 30\%) than the 3D streams (12\%), which caused elevated amounts of fines $(<20 \mathrm{~mm})$ to adhere to larger particles.

The laboratory analysis showed an average CV of 22 
MJ kg-1 and an ash content of $40 \%$ for the "2D 200-90 mm". To fully determine the quality of the produced RDF, further tests that characterize the generated flue gas and remaining ash should be conducted.

A considerable share of the total excavated waste was made up of the output stream $<90 \mathrm{~mm}$, which was the greatest output stream of the ballistic separator with a share of $80 \%$ (wm). Its amount is expected to increase if the material is dried beforehand. As a further processing step, separating the fines by sieving is advisable to remove inert materials and enrich the WtE-stream with high CV materials, since fines contain a significant amount of inert materials, which are not suitable for RDF production. WtM valorisation of the recovered materials, such as inert materials as construction sand, soil-like materials as cover material for operational landfills or metals for recycling, could be considered for the fine fractions. If the separation of metals, glass and stones is possible, the amount of material that has to be re-landfilled would be decreased significantly.

The results of this study cannot be directly transferred to other landfills because compositions depend on different factors such as the origin of the waste, time of storage and physical conditions of the site. In this study, the ballistic separator shows an enhanced mechanical processing due to the share of CDW, which mostly consists of heavy 3D-materials. Further investigation is required in order to state that different types of waste (industrial waste, MSW and CDW, independently) have the same rate of enrichment of high calorific materials as in this study.

Although this study assesses the technical aspects by characterizing the different output streams generated by the ballistic separator, cost efficiency also needs to be taken into account when considering the feasibility of a fullscale ELFM project. Additionally, a remaining challenge is the assessment of costs and revenues of a recovery process by estimating the total amount of deposited waste and relating it to the market prices of the recoverable materials.

\section{ACKNOWLEDGEMENTS}

The authors would like to acknowledge the financial support from the European Union's EU Framework Programme for Research and Innovation Horizon 2020 under Grant Agreement No 721185. Special gratitude is due to the team of Stadler ${ }^{\circledR}$ Anlagenbau $\mathrm{GmbH}$ for the knowledge, expertise and support provided during the material processing with the STT 6000 ballistic separator. The authors are grateful to the personnel from Renewi Belgium SA/NV for their extensive collaboration during the excavation work at the MSG landfill and to Christin Bobe from the Research Group Soil Spatial Inventory Techniques (Ghent University) for its geophysical exploration prior to the excavation that helped to determine the area of interest.

\section{REFERENCES}

Bauer, M., Lehner, M., Schwabl, D., Flachberger, H., Kranzinger, L., Pomberger, R., \& Hofer, W. (2018). Sink-float density separation of post-consumer plastics for feedstock recycling. Journal of Material Cycles and Waste Management, 20(3), 1781-1791.
Beel, H. (2017). Sortierung von schwarzen Kunststoffen nach ihrer Polymerklasse mit Hyperspectral-Imaging-Technologie: Recycling und Rohstoffe. Neuruppin: TK Verlag Karl Thomé-Kozmiensky.

Bhatnagar, A., Kaczala, F., Burlakovs, J., Kriipsalu, M., Hogland, M., \& Hogland, W. (2017). Hunting for valuables from landfills and assessing their market opportunities. A case study with Kudjape landfill in Estonia. Waste management \& research : the journal of the International Solid Wastes and Public Cleansing Association, ISWA, 35(6), 627-635.

Bureau d'études greisch (2002). Interview with Centre d'Enfouissement Technique de Mont-Saint-Guibert: Etude des conséquences de l'octroi du permis d'urbanisme du 29.10.01 sur les conditions d'exploitation du permis du 16.12.98.

Department of Processing and Recycling (2014). Retrieved October 13, 2018, from https://www.iar.rwth-aachen.de/cms/IAR/ Forschung/-Experimentelle-Arbeiten/ efnu/Technikum/lidx/1/.

DIN 51900-1 (2000). Determination of gross calorific value by the bomb calorimeter and calculation of net calorific value.

DIN CEN/TS 15414-1 (2010). Solid recovered fuels - Determination of moisture content using the oven dry method.

DIN EN 15359 (2005). Solid recovered fuels -Specifications and classes.

Energy research Centre of the Netherlands (2018). Phyllis2, database for biomass and waste, from Energy research Centre of the Netherlands: https://www.ecn.nl/phyllis2.

European Parliament (2013). Decision No 1386/2013/EU of the European Parliament and of the Council of 20 November 2013 on a General Union Environment Action Programme to 2020 Living well, within the limits of our planetText with EEA relevance. In Official Journal of the European Union.

García López, C., Küppers, B., Clausen, A., \& Pretz, T. (2018). Landfill mining: A case study regarding sampling, processing and characterization of excavated waste from an Austrian Landfill. Detritus, 2(1), 29.

Giani, H., Fidalgo Estevez, R., Kaufelf, S., Althaus, M., \& Pretz, T. (Eds.). 2016. Technical-economic evaluation of an advanced MBT process to enrich biomass as renewable fuel. Cyprus.

Hermann, R., Baumgartner, R. J., Sarc, R., Ragossnig, A., Wolfsberger, T., Eisenberger, M., et al. (2014). Landfill mining in Austria: Foundations for an integrated ecological and economic assessment. Waste management \& research : the journal of the International Solid Wastes and Public Cleansing Association, ISWA, 32(9 Suppl), 48-58.

Hernández Parrodi, J. C., García López, C., Raulf, K., Pretz, T., Küppers, B., \& Vollprecht, D. (2018b). Characterization of Fine Fractions from Landfill Mining - A Case Study of a Landfill Site in Belgium. VORTRÄGE-Konferenzband zur 14. Recy \& DepoTech-Konferenz. (14), 569-576.

Hernández Parrodi, J. C., Vollprecht, D., \& Pomberger, R. (2018a). Characterization of Fine Fractions from Landfill Mining - A Review of Previous Investigations. Detritus, 2(1), 46.

Hogland, M., Marques, M., 2010. Enhanced Landfill Mining: Material recovery, energy utilisation and economics in the EU (Directive) perspective. In: Proceedings of the International Academic Symposium on Enhanced Landfill Mining. Molenheide, Belgium.

Hull, R. M., Krogmann, U., \& Strom, P. F. (2005). Composition and Characteristics of Excavated Materials from a New Jersey Landfill. Journal of Environmental Engineering, 131(3), 478-490.

Jani, Y., \& Kaczala, F., Marchand, C., Hogland, M., Kriipsalu, M., Hogland, W., \& Kihl, A. (2016). Characterisation of excavated fine fraction and waste composition from a Swedish landfill. Waste Management \& Research, 34 (12), 1292-1299.

Jones, P. T., Geysen, D., Tielemans, Y., van Passel, S., Pontikes, Y., Blanpain, B., et al. (2013). Enhanced Landfill Mining in view of multiple resource recovery: A critical review. Journal of Cleaner Production, 55, 45-55.

Kaartinen, T., Sormunen, K., \& Rintala, J. (2013). Case study on sampling, processing and characterization of landfilled municipal solid waste in the view of landfill mining. Journal of Cleaner Production, $55,56-66$.

Kranzinger, L., Schopf, K., Pomberger, R., \& Punesch, E. (2017). Case study: Is the 'catch-all-plastics bin' useful in unlocking the hidden resource potential in the residual waste collection system? Waste management \& research : the journal of the International Solid Wastes and Public Cleansing Association, ISWA, 35(2), 155-162. 
Kuchta, K., Hobohm, J., \& Flamme, S. (2017). Verwertung von Altprodukten und Abfällen. In: KRANERT, Martin (Hrsg.): Einführung in die Kreislaufwirtschaft : Planung -- Recht -- Verfahren, 253-293.

Martens, H., \& Goldmann, D. (2016). Recyclingtechnik: Fachbuch für Lehre und Praxis (2. Aufl. 2016). Wiesbaden: Springer Fachmedien Wiesbaden.

Maul, A., \& Pretz, T. (2016). Landfill Mining from the processing perspective - a view on mass balance and output streams. Proceeding "3rd International Academic Symposium on Enhanced Landfill Mining, ELFM III", Lisboa (Portugal).

Ministerium für Umwelt und Forsten Rheinland-Pfalz (1983). LAGA - RL. PN 2/78K - Grundregeln für die Entnahme von Proben aus Abfällen und abgelagerten Stoffen. Richtlinie für das Vorgehen bei physikalischen und chemischen Untersuchungen im Zusammenhang mit der Beseitigung von Abfällen.

Ministerium für Umwelt und Forsten Rheinland-Pfalz (2001). LAGA PN 98 - Richtlinie für das Vorgehen bei physikalischen, chemischen und biologischen Untersuchungen im Zusammenhang mit der Verwertung/Beseitigung von Abfällen.

Quaghebeur, M., Laenen, B., Geysen, D., Nielsen, P., Pontikes, Y., van Gerven, T., \& Spooren, J. (2013). Characterization of landfilled materials: Screening of the enhanced landfill mining potential. Journal of Cleaner Production, 55, 72-83.

Rotter, V. S., Lehmann, A., Marzi, T., Möhle, E., Schingnitz, D., \& Hoffmann, G. (2011). New techniques for the characterization of refuse-derived fuels and solid recovered fuels. Waste management \& research : the journal of the International Solid Wastes and Public Cleansing Association, ISWA, 29(2), 229-236.
Seifert, H., \& VEHLOW, J. (2017). Thermische Verfahren In: KRANERT, Martin (Hrsg.): Einführung in die Kreislaufwirtschaft : Planung -Recht --, 5 Wiesbaden : Springer Fachmedien Wiesbaden, 423-470. Sigmund, U. (2018). Sorting with ballistic separators. 4th International Symposium on Enhanced Landfill Mining, 89-94.

van Vossen, W. J., \& Prent, O. J. (2011). Feasibility study: Sustainable material and energy recovery from landfills in Europe. Proceedings Sardinia 2011. Thirteenth International Waste Management and Landfill Symposium. 3 - 7 Oct., 247-248.

Wolfsberger, T., Aldrian, A., Sarc, R., Hermann, R., Höllen, D., Budischowsky, A., et al. (2015b). Landfill mining:: Resource potential of Austrian landfills-Evaluation and quality assessment of recovered municipal solid waste by chemical analyses. Waste management \& research : the journal of the International Solid Wastes and Public Cleansing Association, ISWA, 33(11), 962-974.

Wolfsberger, T., Nispel, J., Sarc, R., Aldrian, A., Hermann, R., Höllen, D., et al. (2015a). Landfill mining:: Development of a theoretical method for a preliminary estimate of the raw material potential of landfill sites. Waste management \& research : the journal of the International Solid Wastes and Public Cleansing Association, ISWA, 33(7), 671-680.

\section{APPENDIX A}

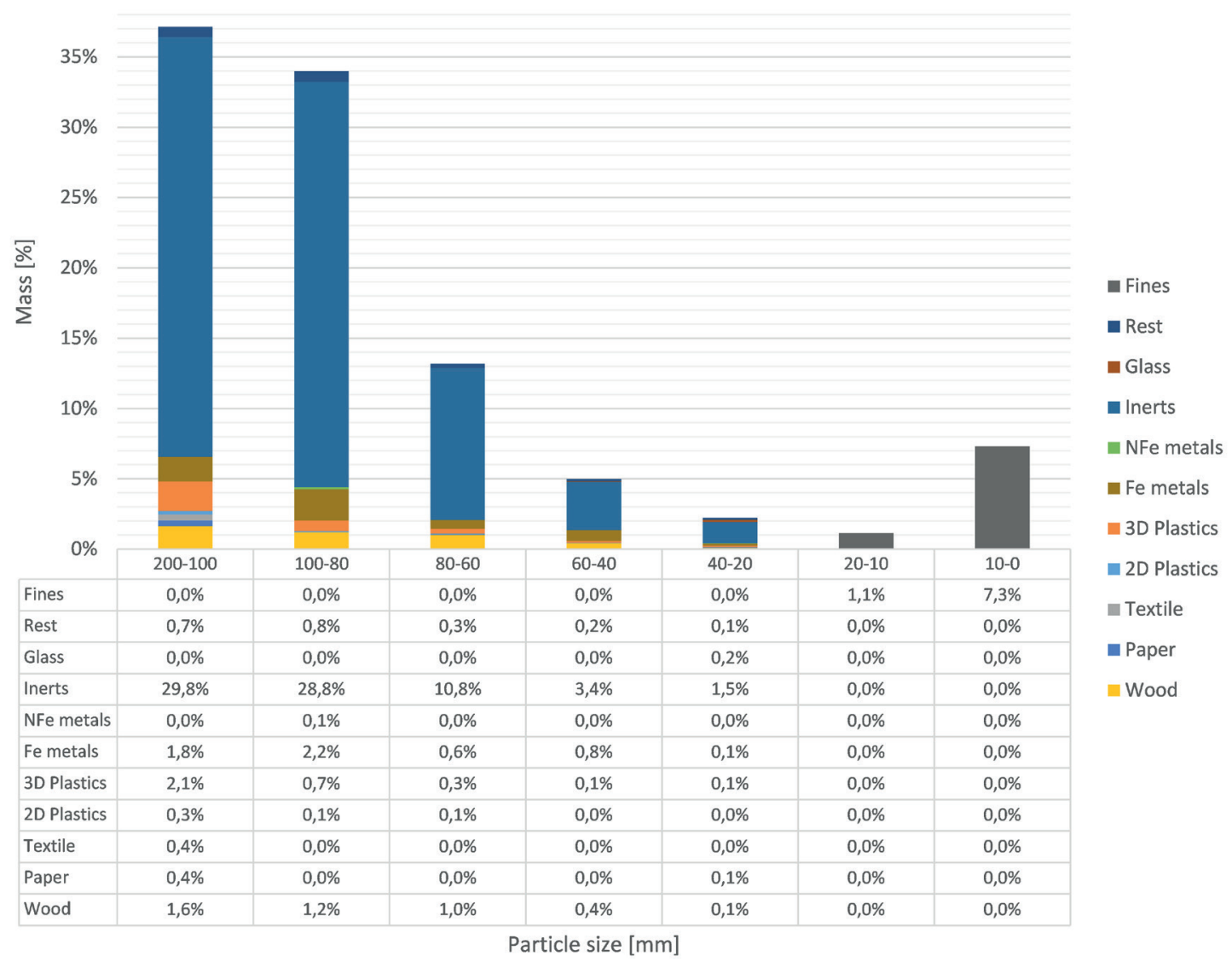

FIGURE A1: Total mass composition, dm \%, by particle size of the output "3D 200-90 mm". 


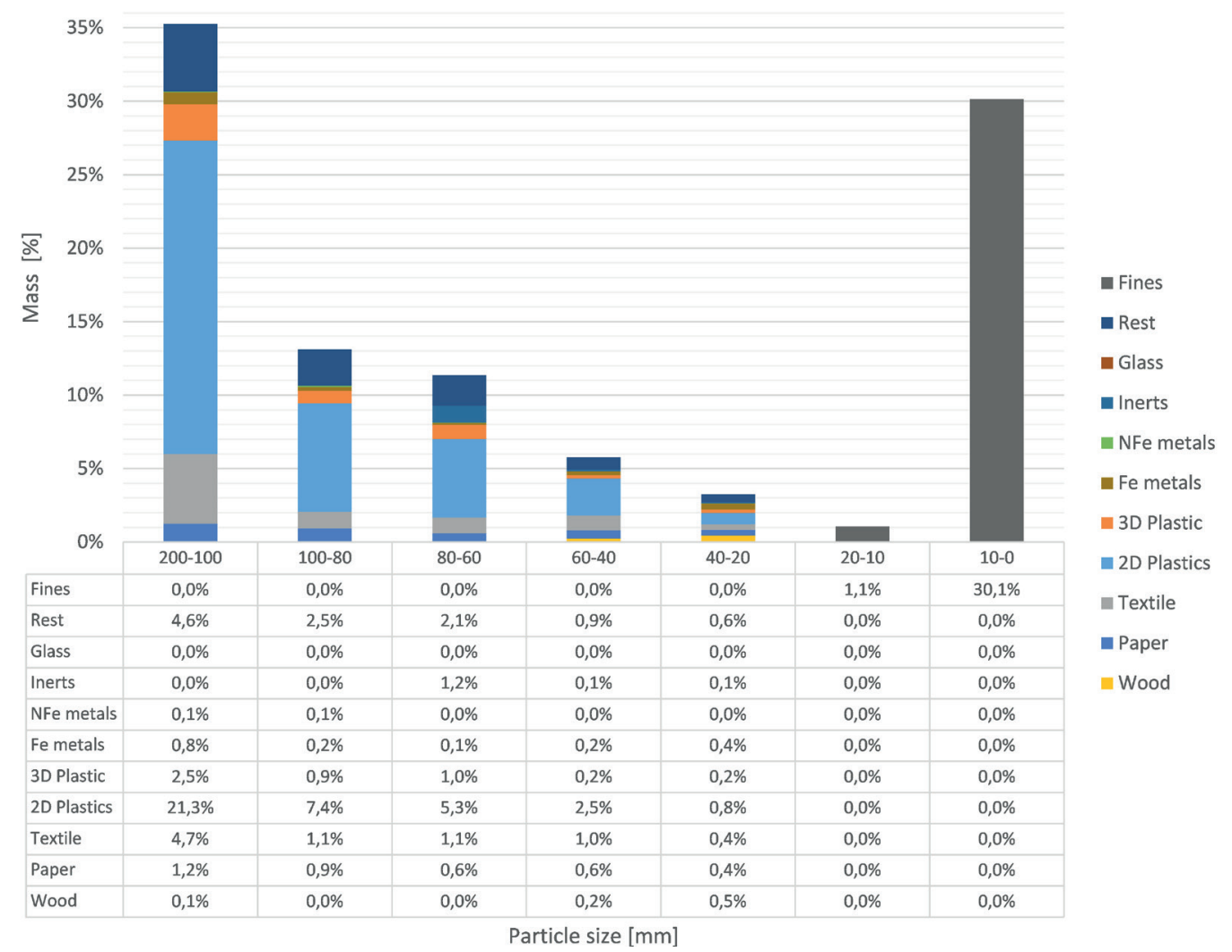

FIGURE A2: Total mass composition, dm \%, by particle size of the output "2D 200-90 mr

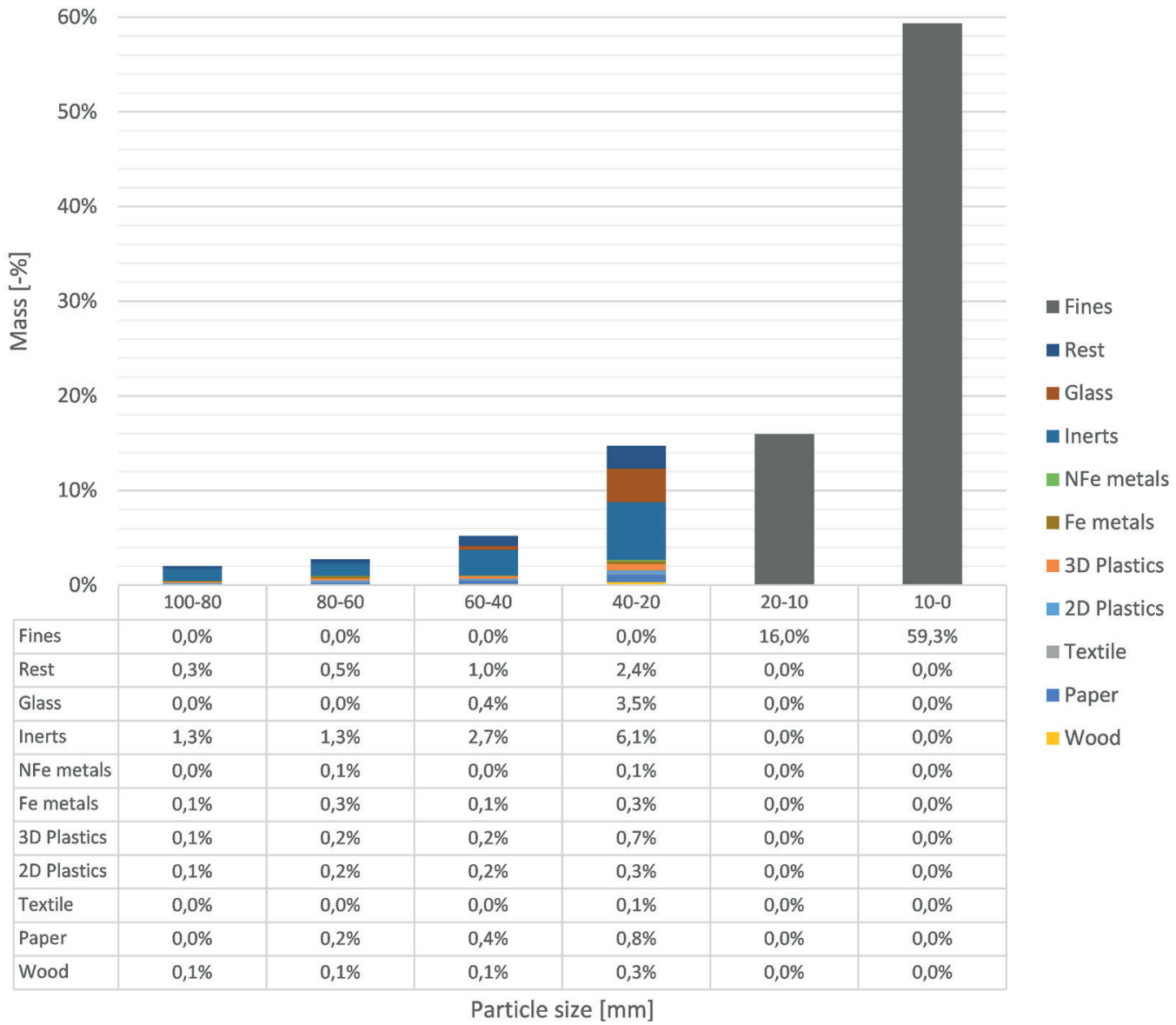

FIGURE A3: Total mass composition, $\mathrm{dm} \%$, by particle size of the output " $<90 \mathrm{~mm}$ ". 


\section{APPENDIX B}

TABLE B1: Technical specifications of the ballistic separator.

\begin{tabular}{l:l}
\hline Manufacturer & STADLER ${ }^{\circledR}$ \\
\hline Modell & STT 6000 \\
\hline Dimensions $(\mathrm{L} \times \mathrm{W} \times \mathrm{H})(\mathrm{mm})$ & $6030 \times 2970 \times 6040$ \\
\hdashline Weight $(\mathrm{kg})$ & 25000 \\
\hline Engine output $(\mathrm{kW})$ & 30 \\
\hline Adjustable Angle & $15^{\circ} ; 17.5^{\circ} ; 20^{\circ}$ \\
\hline Surface $\left(\mathrm{m}^{2}\right)$ & 14.3 \\
\hline Maximum output $\left(\mathrm{m}^{3} / \mathrm{h}\right)$ & 200 \\
\hdashline $\mathrm{N}^{\circ}$ of paddles & 5 \\
\hline $\mathrm{N}^{\circ}$ of fans & No fans available \\
\hline
\end{tabular}

TABLE B2: Technical specifications of the sieves.

\begin{tabular}{|c|c|c|}
\hline & Drum sieve & Box sieve \\
\hline Manufacturer & $\begin{array}{l}\text { Self-made by the Department of Processing and Recycling } \\
\text { (RWTH Aachen University) }\end{array}$ & Siebtechnik \\
\hline Type of movement & Rotating & Circular Vibratory Screen \\
\hline Input power (kW) & 2.2 & 0.75 \\
\hline Diameter of drum screen $(\mathrm{mm})$ & 1500 & - \\
\hline Installation & Polygonal screen with 8 screen linings & - \\
\hline Dimensions of screen linings $(\mathrm{mm})$ & $950 \times 560$ & $500 \times 500$ \\
\hline Revolution & Adjustable & 1400 RPM \\
\hline Mesh sizes (mm) & $10 ; 20 ; 40 ; 60 ; 80 ; 100 ; 120 ; 140 ; 160 ; 200 ; 240 ; 300$ & $1 ; 2 ; 4 ; 6.3 ; 10 ; 20 ; 31.5 ; 40 ; 50 ; 60 ; 80 ; 100$ \\
\hline
\end{tabular}

TABLE B3: Technical specifications of the sieves.

\begin{tabular}{|c|c|c|c|}
\hline Type of cutting mill & Large cutting mill & Small cutting mill & Disc mill \\
\hline Manufacturer & Reto & Dreher & Retsch \\
\hline Input power (kW) & 37 & 2.2 & 1.75 \\
\hline Rotor peripheral speed (m/s) & 9 & 10 & 10 \\
\hline Rotor cutting diameter (mm) & 350 & 160 & \\
\hline Rotor length (mm) & 450 & 200 & \\
\hline Mesh sizes (mm) & $4 ; 5 ; 6 ; 8 ; 10 ; 12 ; 15 ; 20 ; 30 ; 40 ; 50 ; 60 ; 70 ; 80$ & $1 ; 2 ; 3 ; 4 ; 5 ; 6 ; 8$ & $\mathbf{0 . 5} ; 0.75 ; 1 ; 1.5 ; 2 ; 4 ; 6 ; 8 ; 10$ \\
\hline
\end{tabular}

TABLE B4: Technical specifications of the hammer mills.

\begin{tabular}{|c|c|c|}
\hline & Large hammer mill & Small large mill \\
\hline Manufacturer & Hazemag & Condux \\
\hline Type of crusher & High speed & High speed \\
\hline Main types of loads & - & Impact, Shearing \\
\hline Weight (kg) & - & 30 \\
\hline Input power (kW) & 18 & 3 \\
\hline Revolution & adjustable up to approx. $19 \mathrm{~m} / \mathrm{s}$ & 2850 RPM \\
\hline \multicolumn{3}{|l|}{ Mesh sizes (mm) } \\
\hline Feed grain size (mm, max.) & approx. $360 \times 280$ & $100 \times 60$ \\
\hline Rotor width (mm) & - & 150 \\
\hline
\end{tabular}

